\title{
A probabilistic model of chronological errors in layer-counted climate proxies: applications to annually banded coral archives
}

\author{
M. Comboul ${ }^{1}$, J. Emile-Geay ${ }^{1}$, M. N. Evans ${ }^{2}$, N. Mirnateghi ${ }^{1}$, K. M. Cobb ${ }^{3}$, and D. M. Thompson ${ }^{4}$ \\ ${ }^{1}$ Department of Earth Sciences, University of Southern California, 3651 Trousdale Parkway, ZHS 275, Los Angeles, \\ California 90089, USA \\ ${ }^{2}$ Department of Geology, University of Maryland, College Park, Maryland 20742, USA \\ ${ }^{3}$ Department of Earth and Atmospheric Sciences, Georgia Institute of Technology, 311 Ferst Drive, Atlanta, \\ Georgia 30332, USA \\ ${ }^{4}$ Department of Geosciences, University of Arizona, 1040 E. 4th Street, Tucson, Arizona 85721, USA \\ Correspondence to: M. Comboul (comboul@usc.edu)
}

Received: 7 October 2013 - Published in Clim. Past Discuss.: 31 October 2013

Revised: 11 February 2014 - Accepted: 6 March 2014 - Published: 25 April 2014

\begin{abstract}
The ability to precisely date climate proxies is central to the reconstruction of past climate variations. To a degree, all climate proxies are affected by age uncertainties, which are seldom quantified. This article proposes a probabilistic age model for proxies based on layer-counted chronologies, and explores its use for annually banded coral archives. The model considers both missing and doubly counted growth increments (represented as independent processes), accommodates various assumptions about error rates, and allows one to quantify the impact of chronological uncertainties on different diagnostics of variability. In the case of a single coral record, we find that time uncertainties primarily affect high-frequency signals but also significantly bias the estimate of decadal signals. We further explore tuning to an independent, tree-ring-based chronology as a way to identify an optimal age model. A synthetic pseudocoral network is used as testing ground to quantify uncertainties in the estimation of spatiotemporal patterns of variability. Even for small error rates, the amplitude of multidecadal variability is systematically overestimated at the expense of interannual variability (El Niño-Southern Oscillation, or ENSO, in this case), artificially flattening its spectrum at periods longer than 10 years. An optimization approach to correct chronological errors in coherent multivariate records is presented and validated in idealized cases, though it is found difficult to apply in practice due to the large number of solutions. We close with a discussion of possible extensions of this model and connections to existing strategies for modeling age uncertainties.
\end{abstract}

\section{Introduction}

A peculiar feature of the Earth sciences is that the independent variable used to peer into Earth's past (the age of the sample) is always uncertain to some degree. In paleoclimatology, time uncertainties depend on the record's structure, which belongs to one of two categories:

1. Tie-point chronologies, which include most sedimentary and speleothem archives. Such records are dated via a one-to-one mapping between sample depth and age (that is, an age model). This model typically assumes a piecewise-continuous accumulation rate, constrained by a relatively small number of radiometrically determined tie points (e.g., ${ }^{14} \mathrm{C}$ dates for sedimentary archives, or U/Th dates for speleothem archives). Alternatively, when radiometric dating proves impossible, records are often dated by "tuning" to a reference chronology, either derived astronomically (orbital tuning; e.g., Bender, 2002; Hays et al., 1976; Lisiecki and Raymo, 2005; Martinson et al., 1982) or derived from a better-constrained chronology such as the GISP2 record (Grootes et al., 1993) or the Hulu Cave chronology (Wang et al., 2001).

2. Layer-counted chronologies, for instance tree rings, varved sediments, ice cores, some speleothems and annually banded corals. For such records, a chronology is obtained by equating the layer count with the number of years or seasons of archive accumulation 
elapsed since the creation of the topmost (most recent) observed layer. Equivalently, layers may be identified through observation of a seasonally or annually varying quantity such as isotopic composition (Fairbanks and Dodge, 1979). Layer-counted chronologies are assigned ages relative to a modern tie point unless supplemented by independent age controls, such as by radiometric dating (e.g., Cobb et al., 2003; Shen et al., 2013), and often assume continuous time resolution unless observations indicate otherwise (e.g., St. George et al., 2013).

Although records from banded archives can often reach subannual precision, they are not time certain and these uncertainties can have a large influence on variability and coherence between the records. Tree-ring chronologies are generally considered the most accurately dated, because - unlike other proxy types - they are often built from a large number of records. Nonetheless, they require adjustments (crossdating) to optimize coherence across nearby sites (e.g., Douglass, 1941; Fritts, 1976; Wigley et al., 1987; Cook and Kairiukstis, 1990; Yamaguchi, 1991; Stokes and Smiley, 1996). Similarly, although the quoted uncertainty on ice core layer counting is typically on the order of $2 \%$ (Alley et al., 1997b), this value reflects the reproducibility from one chronologist to the next, not the uncertainty about the true date. Seimon (2003) thus showed how two nearby Andean ice cores (Thompson et al., 1985) differed widely when plotted against their published timescales, but that simple adjustments based on volcanic tephra markers could bring the records into excellent agreement. Finally, Emile-Geay et al. (2013) showed how minor age uncertainties in several highresolution records (in particular coral chronologies) could mute interannual signals in a multiproxy reconstruction of tropical Pacific sea surface temperature.

Time uncertainties pose a serious challenge to the analysis of paleoclimate signals, as the mathematical machinery devoted to time series analysis (e.g., spectral analysis, singular spectrum analysis, wavelet analysis) or multivariate analysis (e.g., principal component analysis, regression analysis, climate field reconstruction) implicitly assumes a perfectly known time axis. In the non-banded case, this problem was recognized early on and motivated the use of tuning, though this approach is not without dangers (Blaauw, 2012). Recently, several studies have chosen instead to explicitly take time uncertainties into account (Huybers and Wunsch, 2004; Blaauw, 2010; Haam and Huybers, 2010; Blaauw and Christen, 2011; Rhines and Huybers, 2011; Breitenbach et al., 2012; Anchukaitis and Tierney, 2012), which has greatly helped quantifying the uncertainties inherent to the interpretation of climate signals in such records.

To our knowledge, banded records have not spurred similar modeling efforts, with the notable exception of Rhines and Huybers (2011), whose model targeted long ice-core chronologies like that of GISP2 (Alley et al., 1997b). Their study used a discrete random walk, which assumes that the probability of missing a band, or counting a band twice, is symmetric. However, these probabilities are likely asymmetric for most proxies. Further, the model forced the authors to make some unphysical choices in order to match published estimates of age uncertainties. The model we propose is formulated more intuitively in terms of the probabilities of miscounting a band, and naturally allows for asymmetries in the probability of missing or doubly counting a band. Our work also applies the model to multivariate data sets and explores ways to correct for age errors using information shared amongst similar records.

Since dendroclimatology has dealt with layer-counted chronological errors for decades, it would be tempting to draw from their extensive literature for other proxy classes. Unfortunately, extending dendrochronological techniques to other proxy types spanning large spatial scales is problematic, because cross-dating relies on the existence of a strong common signal shared among series. This assumption is well suited to trees within a restricted biome but may no longer be valid for other proxy types with banded age models (ice cores, annually banded corals, varved sedimentary records), either because too few (if any) replicates are available at a given site or because one is interested in synchronizing records across a wide geographical area (e.g., a pan-Pacific coral network), where the common signal may be weaker. Nevertheless, this approach was successfully applied to replicated coral records from the reefs offshore of Amédée Island, New Caledonia (DeLon et al., 2007; DeLong et al., 2013), and from the Gulf of Mexico (DeLong et al., 2011).

In this article we propose a new probabilistic age model for layer-counted records (Sect. 2.1) and use it to quantify the consequences of such errors in single- and multiproxy applications. Implicit in our approach is the assumption that optimal sampling strategies were utilized, so chronological errors are a leading source of uncertainty. We first use the model to quantify the uncertainty associated with spectral estimates from univariate coral series (Sect. 2.2). We then generalize this framework to the multivariate setting (Sect. 3.1), evaluating the impact of chronological uncertainties on principal component analysis derived from a pan-Pacific coral network (Sect. 3.3). Leveraging the mutual information from these signals, we then propose a method to correct for age uncertainties in banded records (Sect. 4), which we validate on synthetic data. Discussion follows in Sect. 5.

\section{Banded age model: design and application}

\subsection{Univariate model formulation}

We denote a banded time series as $\{\boldsymbol{x}, t\}$, where $\boldsymbol{x}$ is the sequence of $n$ observations and $t$ its corresponding chronology (i.e., the $i$ th measurement $x_{i}$ is assigned a time $t_{i}$ for $i$ taking values in $\{1, \ldots, n\})$. The time axis is modeled as follows: starting from the most recent observation (collection date) 
$t_{1}=t_{\mathrm{f}}$, whose date is assumed to be known exactly, earlier times are deduced by assuming that observations are consecutive (see Fig. 1), so previous observations $t_{i}, i \in\{2, \cdots, n\}$ follow the relation

$t_{i}=t_{i-1}-\Delta_{i}$,

where $\boldsymbol{\Delta}$ is a vector of time increments taking integer values. In this study, we do not consider records derived from multiple-year sampling intervals (Linsley et al., 2006, 2008) nor bulk averages (Hendy et al., 2002; Calvo et al., 2007), which are straightforward extensions of our model. Thus, for error-free annually banded proxies, $\Delta_{i}=\Delta=1$ year exactly (Fig. 1a). Several sources of error, however, may perturb this ideal chronology. For instance, a coral may fail to form a band during a year of particularly poor growing conditions (related to water turbidity, excessive temperature, or other ecological factors) or years may be missing due to sampling artifacts (e.g., core breaks); a tree may fail to form an annual growth increment in an excessively dry or cold year; an ice core may miss a layer due to low deposition or high wind ablation that year; and a varved sediment core may miss a year because of low productivity in that particular year. Conversely, a single (large) coral band, in a fast growth state, may be associated with two (multiple) consecutive years instead of a single one. Additionally, stress bands or changes in growth orientation (e.g., Fig. 1c) may also create "false" secondary bands (see Alibert and Kinsley, 2008; DeLong et al., 2013). Thus, in reality, each entry $\Delta_{i}$ can take any positive integer value (to preserve the layer superposition principle), although $\Delta_{i}=1$ most of the time. Considering that error rates are typically asymmetric (with double counting being more common than missing years; DeLong et al., 2013), we use a stochastic model (Appendix A), in which the increment vector comprises two independent stochastic processes $P^{\theta_{1}}$ and $P^{\theta_{2}}$, with parameters $\theta_{1}$ and $\theta_{2}$, representing the rates of missing and doubly counted bands, respectively.

Age errors are cumulative: for a 100-year-long record, an error rate of $5 \%$ for $\theta_{1}$ and $\theta_{2}$ will lead to offsets as large as \pm 5 years by the beginning of the sequence, with a probability of $\sim 15 \%$ (cf. the shifted initial dates of the perturbed signals in Fig. 2b). Although there is partial compensation between over- and undercounting, leading to a zero expected offset in the symmetric case, this expectation is misleading. Indeed, assuming the independence of age errors from one record to another, there is a roughly $2 \%$ chance that the oldest date of each record will be offset by as many as 10 years (Eq. A7). Though such probability is low, it is non-negligible, and we shall see in Sect. 3.3 that in the case of a multivariate data set it may severely bias the estimation of spatiotemporal modes of variability, far beyond the annual scale.

This error model may be used in two ways, as illustrated in Fig. 2 with simple sinusoidal signals:

i. Starting from an error-free chronology (Fig. 2a), one may perturb it by randomly removing or duplicating

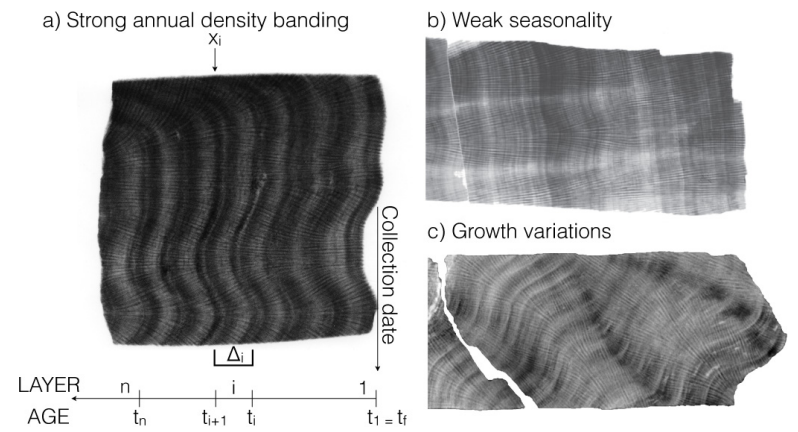

Fig. 1. Coral core X-radiographs: (a) top of a core from Mange Reef, Tanzania (Cole, unpublished). Each layer shows the changing density of the coral growth over a year. Observation $x_{i}$ could be the $\delta^{18} \mathrm{O}$ measured from the $i$ th layer (most likely corresponding to $\Delta_{i}=1$ year). The collection date $t_{1}$ and the oldest one $t_{n}$ are also shown to illustrate our notation; (b) top of a core from Onotoa, Republic of Kiribati (Thompson, unpublished) showing weak seasonality and annual density banding; (c) Fanning Island fossil coral V33, aged $\sim 6500$ years old (Cobb et al., 2013), with a varying growth axis, which typically requires multiple sampling transects.

layers when $P_{i}^{\theta_{1}} \geq 1$ or $P_{i}^{\theta_{2}} \geq 1$, and linearly reassigning time to the corresponding observations (Fig. 2b). This allows one to explore the effect of age errors in idealized scenarios.

ii. Starting from a real chronology, which inevitably contains errors (Fig. 2b), one may use the model to generate plausible corrections, given some knowledge of the miscounting rate (Fig. 2c shows the signals corrected with the true-age model). In this case, extra data entries must be inserted where $P_{i}^{\theta_{1}} \geq 1$, while layers must be removed where $P_{i}^{\theta_{2}} \geq 1$.

The former case requires interpolation of the data where layers are believed to be missing. While linear interpolation is often used for simplicity, it tends to suppress high-frequency variability, hence potentially distorting a record's spectrum. To preserve the intrinsic autocorrelation structure of the time series, we use singular spectrum analysis (SSA; Broomhead and King, 1986; Fraedrich, 1986; Vautard and Ghil, 1989) and its missing value counterpart (SSAM) (Schoellhamer, 2001) to reconstruct the time series including miscounted layers. SSAM was shown to preserve the variance for as many as $\frac{M}{2}$ missing points within a sliding window of size $M$ (Schoellhamer, 2001). In specific applications, other methods would be relevant (e.g., the Lomb-Scargle periodogram (Mudelsee et al., 2009) for spectral analysis with missing data), but interpolating with SSAM allows us to apply other analysis methods without further modification, which will prove useful in multivariate applications (Sect. 3). 


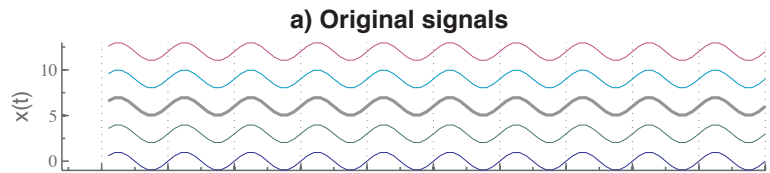

b) Age-perturbed and layer-counted signals

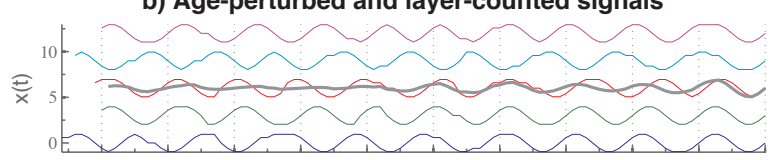

c) Age-corrected signals + SSAM

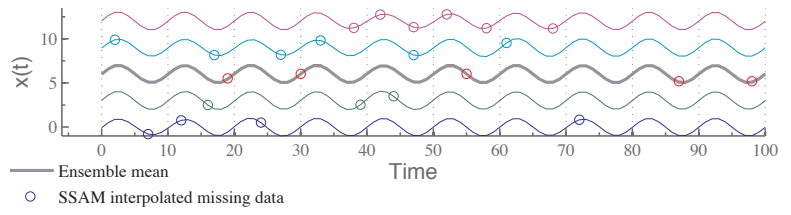

Fig. 2. Illustration of the phase distortion of coherent signals due to miscounted annual bands with $\theta_{1}=\theta_{2}=0.05$ and a collection date $t_{1}=100$. (a) Five hypothetical and identical harmonic signals shifted vertically for clarity; (b) the same signals after introducing age perturbations and making the (erroneous) assumption that 1 layer amounts to 1 year (note the loss of coherency reflected in the ensemble mean in gray, which is performed as part of composites in most climate reconstructions); (c) the same age-perturbed signals, after correcting for miscounted bands and interpolating missing data with SSAM.

\subsection{Uncertainty quantification in coral records}

The above model is now applied to two coral data sets. The first one is the Havannah Island fluorescence record (Isdale et al., 1998), chosen for its particularly long, continuous time span. Because the record already contains dating inaccuracies, we attempt to correct for age errors as explained in Sect. 2.1(ii). The age uncertainty in coral records is not usually known, because many of them are not site-replicated. However, DeLong et al. (2013) suggested an error rate from -2.1 to $3.7 \%$ in unreplicated samples. Error rates may be higher at sites with weak seasonality (Fig. 1b) or in cores with varying growth structures (Fig. 1c). We thus assume a conservative error rate of 0.05 for both missing and doubly counted annual bands (i.e., $\theta_{1}=\theta_{2}=0.05$ ) and generate an ensemble of 1000 plausible age-corrected realizations. The $95 \%$ confidence interval $(\mathrm{CI})$ of the realization ensemble is shown along with the original time series in Fig. 3a.

The corresponding spectral densities were estimated in Fig. 3b using the multi-taper method (MTM; Thomson, 1982) for each age model realization with a conservative time-bandwidth product of $7 / 2$ (results are insensitive to this choice).

It is generally presumed that dating errors should affect the estimation of interannual variance most strongly, but only negligibly affect decadal signals. Figure $3 b$ shows this expectation to be approximately correct, though the impact on decadal variability is substantial. Indeed, the width of the confidence bands roughly triples from periods of 50-5 years.

It is, however, noteworthy that the spectral uncertainties due to the age perturbations (shaded area) are markedly narrower than the uncertainties in the spectral estimates themselves (dashed lines, obtained via standard $\chi^{2}$ intervals), even though a widening of the ensemble spread can be observed as the frequency increases. This result persists with the robust method of Chave et al. (1987) and its associated jackknife intervals.

To check that those results are not an artifact of the choice of coral time series, we repeat this analysis on a $\delta^{18} \mathrm{O}$ record from Palmyra Island (Cobb et al., 2003). Figure 3c shows the cold-season average (December-January-February, DJF) of a continuous splice (1636-1703) of this record, together with the width of the age-perturbed ensemble using $\theta_{1}=$ $\theta_{2}=0.05$. Figure $3 \mathrm{~d}$ shows the impact of age uncertainties on the estimated spectrum, and confirms the previous results: spectral energy of time-uncertain data sets leaks from the interannual band to lower frequencies, but chronological uncertainties generally produce narrower intervals than those due to the spectral estimation process. Although this record was obtained from a fossil sample for which the topmost layer was $\mathrm{U} / \mathrm{Th}$ dated, in this experiment we did not include the U/Th dating uncertainties since no spectral deformation should arise from sliding the whole sequence across the $\mathrm{U} / \mathrm{Th}$ error window.

\subsection{Age model identification}

We have shown how the model described in Sect. 2.1 can be used to generate ensembles of plausible chronologies for any banded record given some a priori estimate of chronological errors. Learning from other data series with more replicated and accurate chronologies can then be used to choose an optimal chronology from an ensemble of plausible chronologies. For example, Li et al. (2011) adjusted age assignments of $\mathrm{U} /$ Th-dated fossil Palmyra Island corals, observing that the correlation between the nominally dated modern record, and the first principal component of the North American Drought Atlas (NADA PC1), interpreted as a proxy for El NiñoSouthern Oscillation (ENSO)-related hydroclimatic variability, was highly significant over the 1891-1994 time period. They then used this property to align the older sequences, before the onset of the instrumental period, to NADA PC1 within the range of $U / T h$ dating error. To identify an optimal chronology, we similarly choose the realization that maximizes the correlation between the Palmyra coral record and the NADA PC1 during their periods of overlap (Fig. 4). As in $\mathrm{Li}$ et al. (2011), we account for the estimated \pm 10 years $\mathrm{U} / \mathrm{Th}$ dating errors by shifting the final time $t_{\mathrm{f}}$ of the ensemble of plausible chronologies generated with our model across a 21-year window, so the ensemble size is 20 times larger than in the known $t_{\mathrm{f}}$ case. For convergence purposes, here we chose to use an ensemble size of $10^{4}$ and the same 


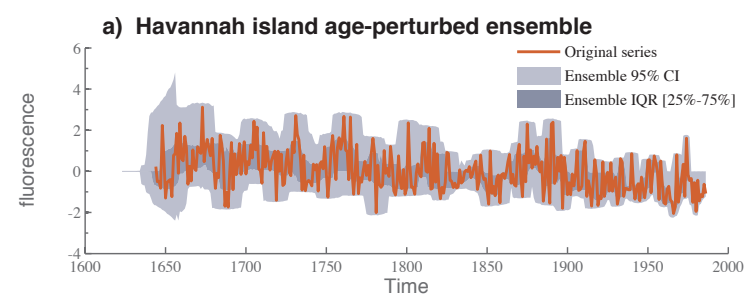

b) Havannah island spectral estimate

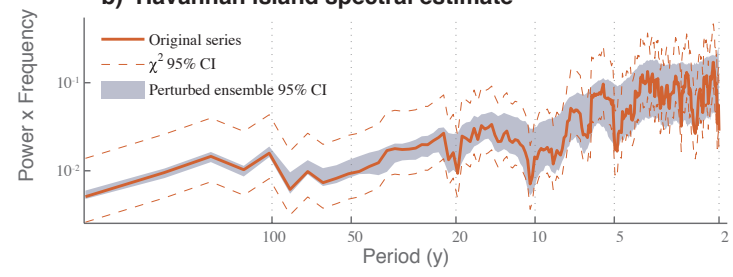

c) Palmyra island age-perturbed ensemble

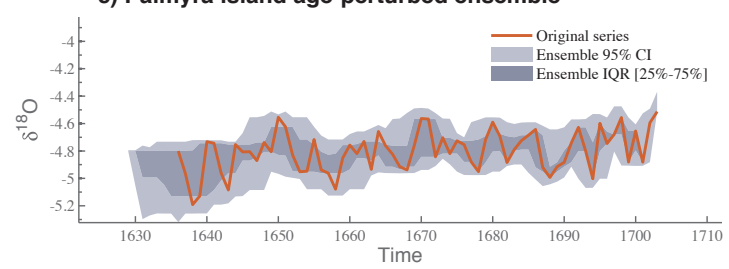

d) Palmyra island (1636-1703) spectral estimate

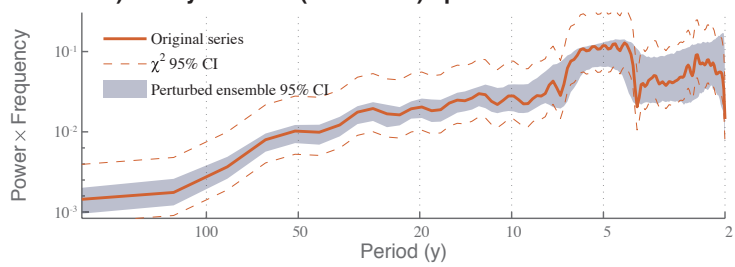

Fig. 3. Ensemble realization (top) and power spectra (bottom) of age-perturbed coral data for (a,b) Havannah Island (Isdale et al., 1998) and (c,d) Palmyra Island $\delta^{18} \mathrm{O}$ record from 1636 to 1703 (Cobb et al., 2003), where the top layer is U/Th dated. The original data and corresponding spectral estimates are shown in red, and the $95 \%$ confidence intervals (CIs) and the $25-75 \%$ interquartile range (IQR) of the perturbed data ensemble and corresponding spectra are shown by the shaded areas. Power spectra are represented in variance-preserving coordinates (that is, the area under the curve is an exact measure of the variance contained in each frequency band).

error rates as in the previous section $\left(\theta_{1}=\theta_{2}=0.05\right)$. The selected chronologies (blue curves in the top Fig. 4) improve the correlation coefficient of the individual series to NADA $\mathrm{PC} 1$ by a factor of 3 relative to the published chronologies (before dating errors were corrected). Those results are comparable to the improvement obtained in Li et al. (2011) after adjustments.

A caveat of this approach is that it assumes a perfectly known NADA PC1 chronology, whereas in reality it is also estimated from layer-counted archives. For a full appraisal of uncertainties in this synchronization process, one would ideally apply this approach to the NADA records as well. However, the large number of cross-dated tree-ring chronologies in NADA (several thousand over this time interval) makes it likely that these uncertainties are negligible compared to those associated with coral dating.

\section{Multivariate generalization}

Climate proxies are increasingly used as part of large-scale data syntheses (e.g., PAGES2K Consortium, 2013; Marcott et al., 2013; Tierney et al., 2013; Tingley and Huybers, 2013). We thus generalize the previous model to the case of a multivariate network and investigate the effect of age errors on the estimation of spatiotemporal modes of climate variability.

\subsection{Model formulation}

Let us consider a multivariate banded data set $\{\boldsymbol{\zeta}, \boldsymbol{\tau}\}$, with $\zeta$ the data matrix containing $n$ proxy measurements at $p$ locations (for instance, $\delta^{18} \mathrm{O}$ or $\mathrm{Sr} / \mathrm{Ca}$ ) and $\tau$ the time matrix. Each entry $\zeta_{\mathrm{ij}},(i, j) \in\{1, \ldots, n\} \times\{1, \ldots, p\}$ corresponds to the $i$ th observation at the $j$ th location, and is assigned a time $\tau_{\mathrm{ij}}=t_{i}^{(j)}$. At each location $j$, miscounting events are repre- sented by independent stochastic processes $P^{\theta_{1 \mathrm{j}}}$ and $P^{\theta_{2 \mathrm{j}}}$ (for missing and double bands, respectively; see Appendix A). This formulation allows different error parameters $\theta_{1 \mathrm{j}}$ and $\theta_{2 \mathrm{j}}$ for each location $j$.

As in Eq. (A3), errors are cumulative and may lead to important age offsets in the earlier portions of the data set. To see this, consider the situation depicted in Fig. 2, which considers five coherent, monochromatic signals. Age errors on these harmonic signals were simulated according to Eq. (A5), using $\theta_{1 \mathrm{j}}=\theta_{2 \mathrm{j}}=0.05$. The figure illustrates how even small age offsets introduce phase distortion that lowers the coherency between signals, producing an apparent amplitude modulation of the periodic component, whose amplitude appears to grow over time. In Sect. 4 we exploit this property to identify age models based on their ability to correct for this loss of coherency.

\subsection{Pseudocoral benchmark}

To illustrate the use of the model described above, and to validate our approach, we need a data set that is free of chronological errors and measurement noise. We thus consider a "pseudocoral" network of 22 corals, derived from simulated climate fields. Pseudocoral locations (Table 1) were chosen to mimic the position of publicly available ${ }^{1}$ coral $\delta^{18} \mathrm{O}$ observations with a resolution better than 2 months (Fig. 5).

The pseudocoral observations $\mathbf{C}=\{\boldsymbol{\zeta}, \boldsymbol{\tau}\}$ were simulated according to the forward model of Thompson et al. (2011), a simple representation of the effects of temperature and sea water isotopic variation on the oxygen isotope composition of coral aragonite:

$$
\zeta_{\mathrm{ij}}=a_{1} \mathrm{SST}_{\mathrm{ij}}+a_{2} \mathrm{SSS}_{\mathrm{ij}}+\sigma \cdot \epsilon_{\mathrm{ij}},
$$

\footnotetext{
${ }^{1}$ http://www.ncdc.noaa.gov/paleo/corals.html
} 

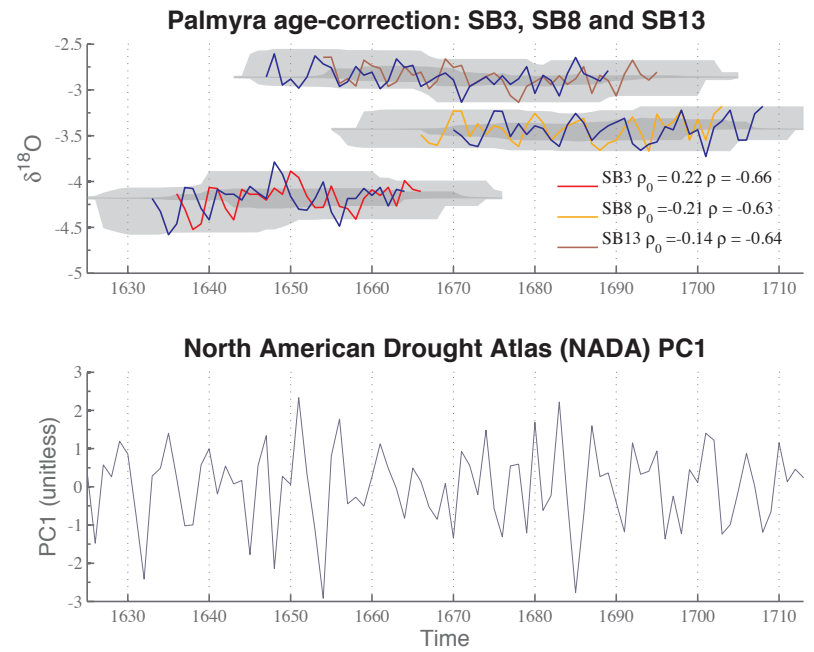

Fig. 4. Palmyra relict coral $\delta^{18} \mathrm{O}$ records (top): published data SB3 in red, SB8 in orange and SB13 in brown (Cobb et al., 2003); the shaded area is the $95 \%$ confidence interval of the ensemble of realizations with final time shifted $t_{\mathrm{f}} \pm 10$ years and $\theta_{1}=\theta_{2}=0.05$, and the blue chronology corresponds to the realizations that maximize the correlation with the first principal component of the NADA record (bottom) over each continuous section. For SB3, there were 2 added years and 2 removed years, and $t_{\mathrm{f}}$ was shifted by -2 years. For SB8, there were 2 added years and 2 removed years, and $t_{\mathrm{f}}$ was shifted by 5 years. For SB13, there were 1 added year and 2 removed years, and $t_{\mathrm{f}}$ was shifted by -6 years. The correlation coefficients with NADA PC1 are also shown, wherein $\rho$ is computed using the aligned Palmyra chronologies, and $\rho_{0}$ using the original chronologies.

where $a_{1}$ and $a_{2}$, locally constant coefficients, describe the dependence of oxygen isotopic equilibrium on the temperature of carbonate formation and the regional relationship between SSS and sea water $\delta^{18} \mathrm{O}$, respectively. $\epsilon \sim \mathcal{N}(0,1)$ is an uncorrelated standard Gaussian white-noise process, and SST and SSS stand for sea surface temperature and sea surface salinity, respectively. Thompson et al. (2011) demonstrated that this simple model of $\delta^{18} \mathrm{O}_{\text {coral }}$ is able to capture the dominant modes of variability observed in corals when driven with instrumental SST and SSS.

The SST and SSS fields were extracted from the CMIP3 "H1" simulation of the Geophysical Fluid Dynamics Laboratory (GFDL) Coupled Model 2.0 (Knutson et al., 2006). The GFDL CM2.0 model is a state-of-the art coupled general circulation model whose performance at simulating tropical Pacific climate is extensively described (Wittenberg et al., 2006; Capotondi et al., 2006; Vecchi et al., 2006; Kug et al., 2010; Xie et al., 2010). Briefly, the model successfully captures the observed annual-mean trade winds and precipitation, sea surface temperature, surface heat fluxes, surface currents, Equatorial Undercurrent, and subsurface thermal structure. CM2.0 displays a robust ENSO with multidecadal fluctuations in amplitude, an irregular period between 2 and 5 years, and a distribution of SST anomalies that is skewed toward warm events as observed. Although the model is limited by biases common to other coupled GCMs, it provides a virtual laboratory of adequate realism to explore the impact of pseudocoral sampling with chronological errors. The data cover the interval $[1860,2000]$; the monthly output was averaged over the DJF months to sample the period of most intense ENSO teleconnections. Our pseudocoral matrix thus contains $n=140$ samples at $p=22$ sites.

In the remainder of the paper, we will use $\mathbf{C}$, the pseudocoral observation matrix and chronology, as a multivariate testing ground for our method - in effect, a perfect model scenario. For this study, we limit ourselves to the noiseless case where $\sigma=0$, though in principle one would have to account for observational noise. Since our interest lies primarily in assessing uncertainties arising from chronological errors, a noise-free matrix is an appropriate first step. We generate an ensemble of age-perturbed realizations of the pseudocoral data set by disturbing the chronology $\boldsymbol{\tau}$ according to the model of Sect. 3.1 using again $\theta_{1}=\theta_{2}=0.05$.

\subsection{Uncertainty quantification}

Inspired by the work of Anchukaitis and Tierney (2012), we first seek to quantify the effect of age uncertainties on the estimation of spatiotemporal modes of variability. Since the CM2.0 model simulates a vigorous ENSO, we seek to answer the following question: were tropical climate variability sampled according to the network of Table 1, how faithfully would ENSO variability be captured in the presence of chronological uncertainties? Figure 5 shows the result of a principal component analysis applied on the error-free network, together with an identical analysis applied to the timeperturbed ensemble. The visualization is analogous to that of Tierney et al. (2013, their Fig. 2).

The unperturbed mode accounts for $25 \%$ of the total variance, and is dominated by the contributions of central and eastern Pacific pseudocorals. Its principal component (PC) is characterized by a concentration of variance in the interannual band (Fig. 5c, red curves), and its spatial structure (light colored dots with white outline) closely matches the SST pattern obtained by regressing the principal component onto the SST field, meaning that SST dominates SSS in Eq. (2), at least on interannual timescales. The same map presents results from the time-uncertain ensemble, showing that in the presence of time uncertainties the vast majority of strong positive loadings (dark-colored disks, circled in black) tend to shrink compared to their unperturbed counterparts (light-colored disks, circled in white). The picture is less clear for negative loadings, but those exert a lesser control on the overall structure. In the age-perturbed ensemble, the amount of variance explained by the ENSO mode ranges between 6 and $10 \%$ (median value: $8 \%$ ) down from $25 \%$ for the error-free data. In such cases, the ENSO mode thus ceases to be the leading mode, as most of its energy is transferred to a trend mode similar to the one identified by Thompson 
Table 1. List of coral locations used for the EOF analysis of Fig. 5. The records were obtained from the database of Emile-Geay and Eshleman (2013) after selecting data sets that record $\delta^{18} \mathrm{O}$ and cover the period $1860-1980$.

\begin{tabular}{|c|c|c|c|c|c|c|}
\hline & Site & Measurement & Latitude & Longitude & Range & Reference \\
\hline 1 & Abrolhos & $\delta^{18} \mathrm{O}$ & $28.46^{\circ} \mathrm{S}$ & $113.77^{\circ} \mathrm{E}$ & 1794-1994 & Kuhnert et al. (1999) \\
\hline 2 & Amedee Light. & $\delta^{18} \mathrm{O}$ & $22.48^{\circ} \mathrm{S}$ & $166.45^{\circ} \mathrm{E}$ & $1660-1993$ & Quinn et al. (1998) \\
\hline 3 & Bunaken & $\delta^{18} \mathrm{O}$ & $1.50^{\circ} \mathrm{N}$ & $124.83^{\circ} \mathrm{E}$ & $1860-1990$ & Charles et al. (2003) \\
\hline 4 & Clipperton Atoll & $\delta^{18} \mathrm{O}$ & $10.30^{\circ} \mathrm{N}$ & $109.00^{\circ} \mathrm{W}$ & 1893-1994 & Linsley et al. (2000) \\
\hline 5 & Guam & $\delta^{18} \mathrm{O}$ & $13.00^{\circ} \mathrm{N}$ & $145.00^{\circ} \mathrm{E}$ & 1790-2000 & Asami et al. (2005) \\
\hline 6 & Ifaty & $\delta^{18} \mathrm{O}$ & $23.14^{\circ} \mathrm{S}$ & $43.58^{\circ} \mathrm{E}$ & $1659-1995$ & Zinke et al. (2004) \\
\hline 7 & La Reunion & $\delta^{18} \mathrm{O}$ & $21.03^{\circ} \mathrm{S}$ & $55.25^{\circ} \mathrm{E}$ & $1832-1995$ & Pfeiffer et al. (2004) \\
\hline 8 & Laing & $\delta^{18} \mathrm{O}$ & $4.15^{\circ} \mathrm{S}$ & $144.88^{\circ} \mathrm{E}$ & 1884-1993 & Tudhope et al. (2001) \\
\hline 9 & Lombok Strait & $\delta^{18} \mathrm{O}$ & $8.25^{\circ} \mathrm{S}$ & $115.50^{\circ} \mathrm{E}$ & $1782-1990$ & Charles et al. (2003) \\
\hline 10 & Madang & $\delta^{18} \mathrm{O}$ & $5.22^{\circ} \mathrm{S}$ & $145.82^{\circ} \mathrm{E}$ & $1880-1993$ & Tudhope et al. (2001) \\
\hline 11 & Mafia & $\delta^{18} \mathrm{O}$ & $8.02^{\circ} \mathrm{S}$ & $39.50^{\circ} \mathrm{E}$ & $1622-1722$ & Damassa et al. (2006) \\
\hline 12 & Mahe & $\delta^{18} \mathrm{O}$ & $4.62^{\circ} \mathrm{S}$ & $55.00^{\circ} \mathrm{E}$ & $1846-1995$ & Charles et al. (1997) \\
\hline 13 & Maiana Atoll & $\delta^{18} \mathrm{O}$ & $1.00^{\circ} \mathrm{N}$ & $173.00^{\circ} \mathrm{E}$ & 1840-1994 & Urban et al. (2000) \\
\hline 14 & Mentawai & $\delta^{18} \mathrm{O}$ & $0.13^{\circ} \mathrm{S}$ & $98.52^{\circ} \mathrm{E}$ & $1858-1997$ & Abram et al. (2008) \\
\hline 15 & Moorea & $\delta^{18} \mathrm{O}$ & $17.50^{\circ} \mathrm{S}$ & $150.00^{\circ} \mathrm{W}$ & $1852-1990$ & Boiseau et al. (1998) \\
\hline 16 & Ningaloo Reef & $\delta^{18} \mathrm{O}$ & $21.91^{\circ} \mathrm{S}$ & $113.97^{\circ} \mathrm{E}$ & $1878-1995$ & Kuhnert et al. (2000) \\
\hline 17 & Palmyra & $\delta^{18} \mathrm{O}$ & $5.88^{\circ} \mathrm{N}$ & $162.00^{\circ} \mathrm{W}$ & $1886-1998$ & Cobb et al. (2001) \\
\hline 18 & Rabaul2006 & $\delta^{18} \mathrm{O}$ & $4.19^{\circ} \mathrm{S}$ & $151.98^{\circ} \mathrm{E}$ & $1867-1997$ & Quinn et al. (2006) \\
\hline 19 & Rarotonga(2R) & $\delta^{18} \mathrm{O}$ & $21.24^{\circ} \mathrm{S}$ & $159.83^{\circ} \mathrm{E}$ & $1726-1996$ & Linsley et al. (2008) \\
\hline 20 & Rarotonga(3R) & $\delta^{18} \mathrm{O}$ & $21.24^{\circ} \mathrm{S}$ & $159.83^{\circ} \mathrm{E}$ & 1874-2000 & Linsley et al. (2006) \\
\hline 21 & Ras Umm Sidd & $\delta^{18} \mathrm{O}$ & $27.85^{\circ} \mathrm{N}$ & $34.31^{\circ} \mathrm{E}$ & $1751-1995$ & Felis et al. (2000) \\
\hline 22 & Secas & $\delta^{18} \mathrm{O}$ & $7.98^{\circ} \mathrm{N}$ & $82.00^{\circ} \mathrm{W}$ & $1707-1984$ & Linsley et al. (1994) \\
\hline
\end{tabular}

a) ENSO mode pseudocoral EOF - $25 \%$ variance

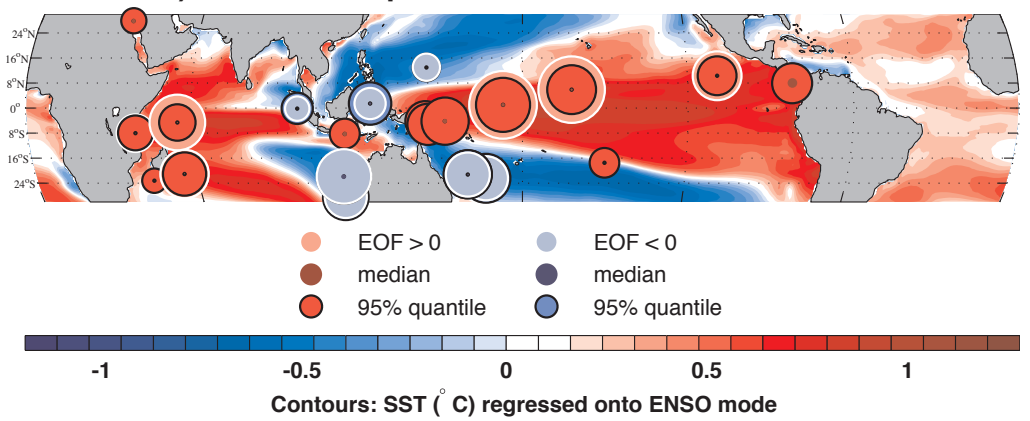

b) ENSO mode PC timeseries

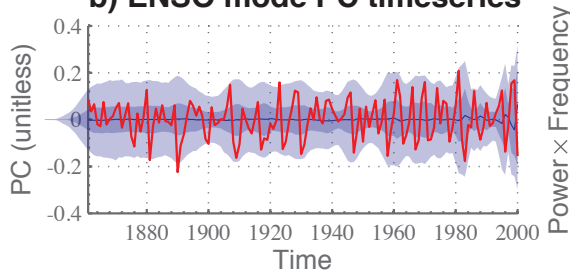

c) ENSO mode PC spectrum

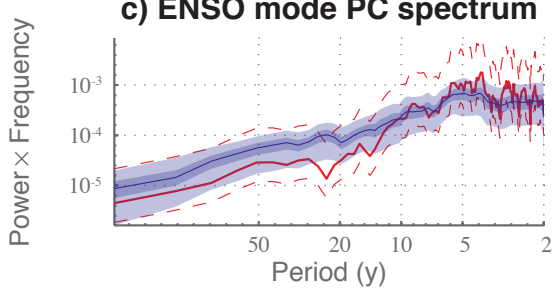

Fig. 5. Spatiotemporal uncertainty quantification on a pseudocoral network. (a) EOF loadings (circles) corresponding to the ENSO mode of an ensemble of age-perturbed pseudocoral records with miscounting rate $\theta=0.05$. EOF loadings for error-free data are shown in light colors circled in white, while the median and $95 \%$ quantile are shown by dark disks and black-circled disks, respectively. Contours depict the SST field associated with the mode's principal component (PC) (b), whose power spectrum is shown in (c). Results for the time-uncertain ensemble are shown in blue: median (solid line), $95 \%$ confidence interval (light-filled area) and interquartile range [25-75\%] (dark-filled area). Results for the original (error-free) data set are depicted by solid red lines. Dashed red lines denote $\chi^{2}$ error estimates for the MTM spectrum of the error-free data set. 
et al. (2011). In our case, the importance of this mode is mainly an artifact of dating errors. A spectral analysis of the age-perturbed PC (Fig. 5c, blue colors) shows a systematic increase in multidecadal variability (10-50-year periods) at the expense of interannual variability. The transfer of power from high to low frequencies may be seen by computing the spectral slope $\beta$, where we fit the model $S(f) \propto f^{\beta}$ to the continuum of each spectrum $(f \leq 1 / 15)$. The spectrum of the unperturbed ENSO PC has a slope $\beta_{\circ}=-0.72$, while the age-perturbed ensemble shows values centered around a median value $\beta_{\mathrm{m}}=-0.22$ with an interquartile range of $[-0.41,0]$. The loss of coherency thus has the effect of flattening the spectrum of the ENSO mode. Even when the error rate is 50 times smaller $(\theta=0.001)$, one still observes that age uncertainties tend to exaggerate multidecadal ( 20 years and longer) variations at the expense of interannual variations (Fig. 6). This may explain why Ault et al. (2009) found, using a similar PCA approach, that their coral network exhibited very energetic variability at such scales, with an amplitude that grew back in time. The presence of small age uncertainties could explain part of the multidecadal power enhancement they observed in the late nineteenth century, since fewer instrumental observations were available to provide chronological anchors to coral time series at that time than in the twentieth century. Our analysis suggests that the accumulation of age model uncertainty is one possible - non-climaticexplanation for this apparent enhancement of low-frequency variability in an all-coral network, though a more detailed investigation (incorporating knowledge of error rates in each of their records) would be required to evaluate this quantitatively.

\section{Coherence-based identification of age models}

As in Sect. 2.3, one would like to choose an optimal chronology among the ensemble of competing age models. To do so, we apply an optimization principle based on the idea that all pseudocorals in our network share some information about a common signal (ENSO in our pseudocoral benchmark). Indeed, coral networks have been shown to record spatiotemporally coherent climate modes (Evans et al., 1998, 2000, 2002), a property shared by our pseudocoral network benchmark (Fig. 5). Moreover, we showed in Sect. 3.3 that chronological errors lead to a loss of coherency among records; that is, we expect age errors to lower interannual coherency among records compared to what it might otherwise be. While chronological uncertainty is not the only source of discrepancies among records (indeed the sampling of corals alone may be challenging due to their biologically mediated origins of layers), several studies (Hendy et al., 2002; DeLon et al., 2007; DeLong et al., 2013) highlight chronological uncertainties associated with coral reconstructions as a main cause for loss of coherency between records. One way to correct for this effect is to pick the age model that maximizes interannual coherency between measurements.

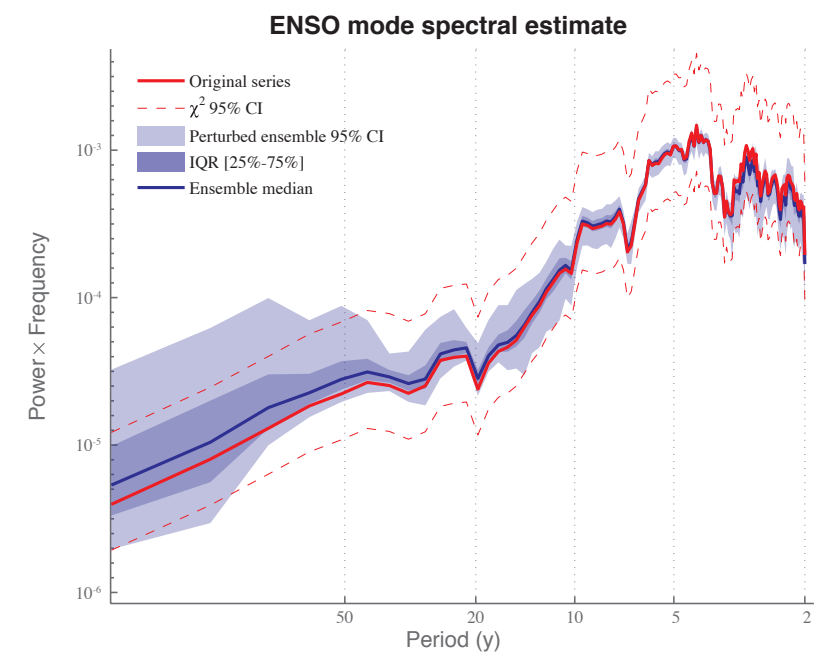

Fig. 6. Spectral density of the ENSO mode PC for $\theta=0.001$. Compare to Fig. 5, bottom right.

This exercise is, however, complicated by the large dimensionality of the space of possible solutions. The dimensionality may be estimated in several ways: assuming that age perturbations follow a Bernoulli process, an $n \times p$ data matrix admits up to $3^{n p}$ age perturbation matrices. This number quickly becomes astronomical, even for moderate $n$ and $p$ (an NP-hard problem). A more relevant measure, however, is the number of solutions for a given error rate. Given a symmetric error rate $\theta_{1}=\theta_{2}=\theta$, one expects, on average, $\left(\frac{n p}{\theta n p}\right)$ (where $\tilde{x}$ denotes the nearest integer of $x$ ) plausible solutions, which induces a serious computational challenge. This is illustrated in Table 2, which charts the number of solutions for various values of $n p$ and $\theta$.

In practice, we generate an ensemble of $L=10^{5}$ time perturbations $\boldsymbol{\Delta}=\left\{\Delta^{(1)}, \Delta^{(2)}, \ldots, \Delta^{(L)}\right\}$ according to Eq. (A5), and choose an optimal chronology amongst those realizations. The optimization principle is described next.

\subsection{Optimization scheme}

Because age errors tend to lower coherency amongst records (Fig. 2), the quantity we seek to maximize is the generalized magnitude squared coherency (GMSC; Chakrabarty et al., 2002; Ramirez et al., 2008, 2010), an extension of the traditional coherency to more than two time series. More precisely, we maximize this quantity over the interannual band, where age perturbations have the largest effect on coherency. The method proceeds as described in Algorithm 1 (Table 3).

\subsection{Method validation}

To check that the above principle can identify the correct age model, we employ the following strategy. A reference age-perturbation process is used to alter the chronology of the error-free pseudocoral data set described in Sect. 3.3. We 
Table 2. Complexity as a function of $\theta$ and the matrix dimension $n p$. Infinity symbols denote numbers that exceed machine capacity.

\begin{tabular}{rccccc}
\hline$n p \mid \theta$ & 0.01 & 0.03 & 0.05 & 0.07 & 0.09 \\
\hline 50 & $2 \times 10^{2}$ & $4 \times 10^{5}$ & $4 \times 10^{8}$ & $10^{11}$ & $3 \times 10^{13}$ \\
100 & $5 \times 10^{4}$ & $1 \times 10^{12}$ & $1 \times 10^{18}$ & $3 \times 10^{23}$ & $2 \times 10^{28}$ \\
1000 & $9 \times 10^{53}$ & $1 \times 10^{132}$ & $5 \times 10^{195}$ & $4 \times 10^{250}$ & $3 \times 10^{299}$ \\
5000 & $1 \times 10^{277}$ & $\infty$ & $\infty$ & $\infty$ & $\infty$ \\
\hline
\end{tabular}

then generate an ensemble of age corrections (Sect. 3.1), for the reference perturbed data set $\mathbf{C}^{*}:=\left\{\boldsymbol{\zeta}^{*}, \boldsymbol{\tau}^{*}\right\}$ yielding an ensemble of candidate age-corrected data sets, and apply the optimization scheme described above. We then verify the validity of our model by comparing the retained chronology to the true one.

For a given $\theta$, the verification algorithm is explained in Algorithm 2 (Table 3).

The results (Fig. 7) show the rapid loss of coherency over the interannual band as more age errors (increasing $\theta$ parameter) are introduced in the time series. Indeed, the $\theta=0.001$ case brings the vast majority of the time-uncertain ensemble spectra under the coherence spectrum of the original time series, and the $\theta=0.05$ case suppresses nearly all the coherency for periods shorter than 4 years, and greatly subdues the original peak around 5 years.

For $\theta=0.05$, the optimization principle failed to identify the correct age model, as no single realization of the corrected ensemble presented high GMSC values in the interannual band. The issue stems from the very high dimensionality of the space of plausible age corrections (Table 2), which results in the inability of our sampled ensembles to span the solution space effectively. We attempted to use a Latin hypercube sampling scheme in an effort to cover the solution space more effectively; however we did not notice any major improvement compared to the Monte Carlo ensemble results. More work is required here to find efficient sampling techniques.

One way to evaluate the potential of this method to accurately portray uncertainties is to compute the actual coverage rates (Guttman, 1970) of CIs derived from our ensemble. To do so, we evaluate the probabilities that the ensemble CIs cover the original data set, and compare those to their nominal value of $95 \%$ (Table 4). As $\theta$ increases, so do time uncertainties, thereby widening the confidence interval of the ensemble. The coverage probability remains high for all $\theta$, since the error-free data lie within the corrected ensemble nearly $98 \%$ of the time. Our CIs are thus slightly conservative.

While the difficulty in solving this NP-hard optimization problem gives little hope of finding the correct age model even for the smallest $\theta$ (note from Table 2 that the expected number of plausible chronologies to correct $1 \%$ age errors is on the order of $10^{15}$ ), we here show that the coherence-based optimization principle can indeed bring the age model closer to the correct one.
To see this quantitatively, one first needs to define a distance over age model space. The Hamming distance $d_{H}(\boldsymbol{x}, \boldsymbol{y})$ (Hamming, 1950) between two vectors $\boldsymbol{x}$ and $\boldsymbol{y}$ in $\mathbb{R}^{n}$ provides such a metric. $d_{H}(\boldsymbol{x}, \boldsymbol{y})$ is defined as the proportion of corresponding coefficients positions in which they differ, i.e.,

$d_{H}(\boldsymbol{x}, \boldsymbol{y})=\frac{1}{n} \sum_{i=1}^{n} d_{i}$,

where

$d_{i}= \begin{cases}1 & \text { if } x_{i}=y_{i} \\ 0 & \text { otherwise }\end{cases}$

Because departures from unity in $\boldsymbol{\Delta}$ are of prime interest, this metric is a good one to differentiate time-shifted records from one another. We generalize the Hamming distance to our matrix case simply by computing and adding together the distances at each location $j$, then dividing by $p$.

In the following experiment, we sample ensembles of chronologies in a restricted neighborhood around a reference age-perturbed data set $\mathbf{C}^{*}$. In this context, for each time perturbation in $\mathbf{C}^{*}$, we sample an age correction within a neighborhood of size $2 * N_{v}+1$, centered around a known miscounted band.

Four age-corrected ensembles are generated using a neighborhood size expanding from $N_{\mathrm{v}}=1$ to $N_{\mathrm{v}}=10$ annual bands on either side of the true one. For each sampled realization, we evaluate the Hamming distance to the errorfree chronology and compute the global coherence spectrum. For each ensemble, we construct its corresponding Hamming distance distribution and extract the realization that maximizes the GMSC according to Algorithm 1 (Table 3). In Fig. 8, the results for each ensemble is color-coded so that one can relate the coherence spectra to the Hamming distance distributions. The green color refers to the reference perturbed data set with an error rate $\theta=0.05$, and the red is reserved for the original time series. The dark blue, blue, pink and light brown show the results for $N_{\mathrm{v}}=1,4,7$, and 10 , respectively. We observe an increase in the mean of the distance distribution as the size of the neighborhood $N_{\mathrm{v}}$ expands, yet for all the realizations the distance to the error-free chronology was reduced relative to the distance between the reference and the true chronologies. This experiment shows that when the age-model ensemble includes the true solution, the optimization principle tends to effectively correct the errors, in the sense that it reduces the Hamming distance between the original and corrected chronologies. On the other hand, the realization that maximizes the GMSC for each neighborhood ensemble does not consistently minimize the Hamming distance (see the vertical bars of the ensemble color in the bottom Fig. 8); however, it, on average, appears on the lower half of each Hamming distance distribution. The black curve in the coherence spectra figure and the line of the same color in the Hamming distance plot refer to 
Table 3. Computational steps to identify an optimal chronology.
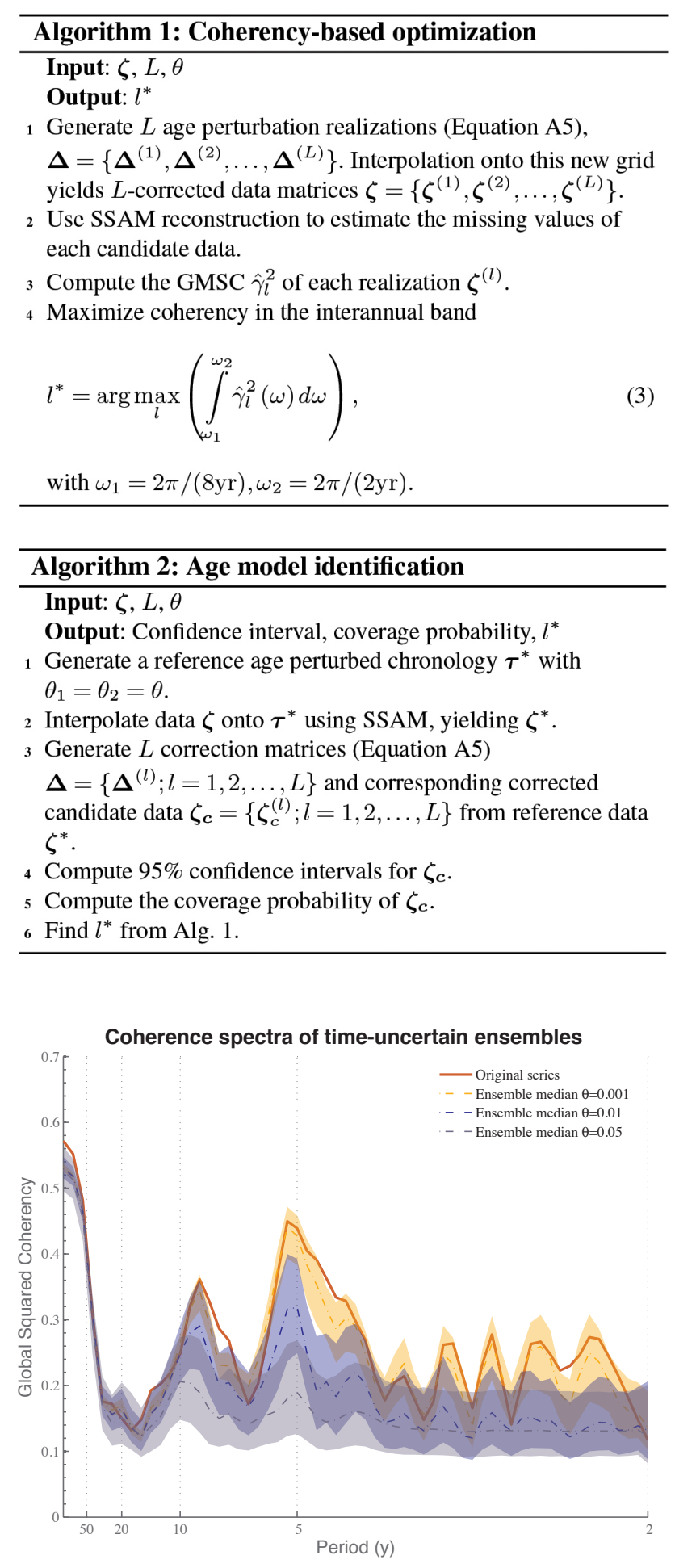

Fig. 7. Global coherence spectra for time-uncertain ensembles generated with $\theta_{1}=\theta_{2}=0.001$ (orange), $\theta_{1}=\theta_{2}=0.01$ (dark blue) and $\theta_{1}=\theta_{2}=0.05$ (gray). The ensemble medians are illustrated in dashed lines, and their corresponding colored patches represent the ensemble $95 \%$ CIs. The thick red curve is the coherence spectrum of the error-free time series.
Table 4. Time-uncertain ensemble $95 \% \mathrm{CI}$ width means $\mu$ and standard deviations $\sigma$, and probabilities of the ensemble CI covering the original data with respect to $\theta$.

\begin{tabular}{llllll}
\hline$\theta$ & 0.01 & 0.03 & 0.05 & 0.07 & 0.09 \\
\hline CI width, $\mu$ & 0.38 & 0.47 & 0.50 & 0.53 & 0.55 \\
CI width, $\sigma$ & 0.18 & 0.17 & 0.17 & 0.16 & 0.17 \\
Coverage rate & 0.97 & 0.99 & 0.97 & 0.98 & 0.98 \\
\hline
\end{tabular}

the realization that achieves the maximum GMSC value, selected from an unrestricted ensemble such as one generated according to Eq. (A5). The sampling issue associated with the extremely high dimensionality of the solution space can be readily observed here, noticing that the realization maximizing the GMSC barely surpasses the reference coherence spectrum in addition to its distance to the original chronology exceeding the distance between the reference and true data. The issue may be alleviated if there is some prior information about the timing of age errors, for instance an observed mismatch between how two series portray an event - like a historic volcanic eruption - that should be synchronous.

\section{Discussion}

In this article, we put forth a probabilistic model for layercounted chronologies. The model was designed for univariate as well as multivariate data sets, and is flexible enough to accommodate location-specific and asymmetric error rates. We used this model to generate ensembles of time-uncertain data sets, which we analyzed using spectral methods and principal component analysis.

In the univariate case, we showed that age perturbations tend to blur variability between interannual and multidecadal scales. In the multivariate case, we showed that even small age offsets between records may significantly lower coherency between records, producing an apparent amplitude modulation of high-frequency signals. These short-term phase interferences thus led to long-term effects, exaggerating low-frequency variability at the expense of interannual signals. This suggests that at least part of the reason for the observed nineteenth century increase in the amplitude of low-frequency variability (Ault et al., 2009) could be the presence of age errors.

We also attempted to correct for age errors using an optimization principle based on the global coherence of a multivariate record. The large dimensionality of the age model space, however, made the random sampling scheme an inefficient method of exploration. There is no easy way around this problem. Nonetheless, we showed that our optimization strategy was able to correct dating errors when sufficient restrictions were placed on the solution space, provided the mutual information was sufficiently strong. 
a) Coherence Spectra with neighborhood size

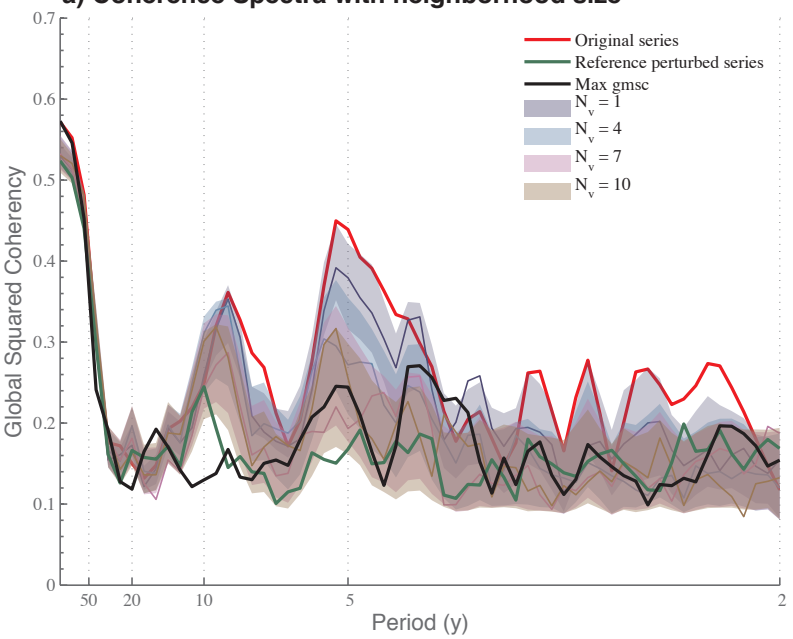

b) Hamming distance distribution with neighborhood size

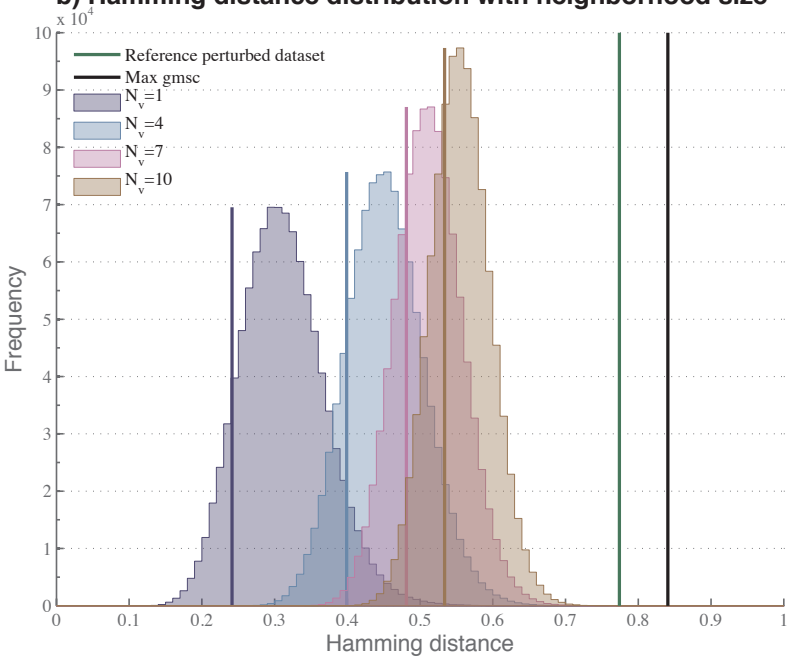

Fig. 8. Coherence spectra (top) and Hamming distance distributions to the original chronology (bottom) for ensembles of chronologies sampled around the reference perturbation matrix (with $\theta=0.05$ ), in restricted neighborhood of sizes $2 * N_{\mathrm{V}}+1$ for $N_{\mathrm{V}}$ increasing from 1 to 10 . The thick red curve represents the coherence spectrum for the error-free data, the results related to the reference perturbed data set are shown in green, and plotted in black are the results for the ensemble realization (sampled across the entire solution space) that maximizes the GMSC for the neighborhood ensembles (shaded areas): the $95 \%$ CIs and Hamming distance distributions, and corresponding realizations maximizing the GMSC (solid lines) are shown in dark blue, blue, pink and light brown for $N_{\mathrm{V}}=1,4,7$ and 10 , respectively.

There are important limitations to our study. First and foremost, our framework assumes that the error rates are known. Ideally, one would estimate the miscounting rate parameters $\left(\theta_{1}, \theta_{2}\right)$ from the data, which could be done in the presence of independent information (replicated annual cycles in multiple types of observations, absolute or independent age information), and/or information such as the cumulative number of material hiatuses, which may be correlated to the likelihood of missing or double-counted events (e.g., Brown et al., 1992; Alley et al., 1997a; Juillet-Leclerc et al., 2006; Alibert and Kinsley, 2008; DeLong et al., 2013). Future work with the uncertainty algorithm might use such information to empirically and adaptively reset accumulated age errors.

We also restricted our analysis to symmetric error rates, which is an unlikely scenario according to DeLong et al. (2013), who emphasized that double counting is typically more common than missing years in coral records from the reefs offshore of Amédée Island. Considering that the events perturbing the chronologies are hidden states of the process and are not being directly measured, a maximum likelihood principle would have to be employed to evaluate the error rate, which substantially complicates the problem of designing a likelihood function. However, when the common signal driving the record is strong enough, a coherencybased Bayesian approach could potentially learn from the data. In this case, one would relax the assumption of known miscounting rate parameters $\left(\theta_{1}, \theta_{2}\right)$ in favor of prior distributions on those parameters, which would incorporate as much scientific information as possible. In this regard, one should note that most geochronologies are developed with the purpose of producing the single best representation of past changes. There would be merit in also providing raw chronologies so that the error rate may be estimated via comparing it with other, absolutely dated records (for instance, historical observations or chronostratigraphic markers). In other words, we urge field scientists to report all the chronological information relevant to the characterization of these error rates, rather than exclusively seeking to reduce them, as this would greatly aid the quantification of uncertainties associated with each record.

Second, we assumed that time perturbations follow a homogeneous Poisson process, with a uniform and symmetric rate for all pseudocorals considered. In nature, each record will display a different rate, and in situations of uneven dating conditions (e.g., annual bands being more or less visible in a given time interval; see Fig. 1b) an inhomogeneous Poisson process would constitute a more suitable model within a single record. The error rate could change with the location and age of the sample, and be informed by local expertise to account for known climatic events that could have affected the coral growth structures. Assessments of where and when corals might have over- or undergrown impose restrictions on the age model space, which would greatly improve the ability of our optimization principle to identify the correct chronology.

Third, we assumed that age perturbations taking place at different locations are independent. Nonetheless, one could easily conceive of a scenario in which a regional phenomenon, such as ENSO extremes, would simultaneously affect the growth of all corals located in one area. The model would therefore have to include regional random time 
perturbations, which could be done by specifying parameters conditional on the climate.

Fourth, we assumed that all records considered had annual resolution, while in reality it could range from a month to several years. Adapting the method to a network of variable resolution would require the conditioning of the error rate parameter $\theta$ on the resolution of the record's chronology. For instance, monthly data tend to present a lower error rate than yearly data, due the presence of a well-defined annual cycle, i.e., a seasonal cycle in $\delta^{18} \mathrm{O}$ in one or more paleodata streams from the coral (and other annually layered archives) that mostly "resets" age model uncertainty at some point in the year. Yet monthly data would add subannual errors from selecting incorrect tie points in the seasonal cycle and from interpolating between tie points (e.g., De Ridder et al., 2004), particularly in regions where the seasonal cycle and annual density banding are weak (e.g., key ENSO-sensitive regions of the central Pacific, Fig. 1b). Likewise, multiple-year sampling intervals could have aliasing consequences that would potentially add to age uncertainties.

Fifth, we assumed that the latest time $t_{\mathrm{f}}$ is known exactly (except in Sect. 2.3), which is only true of records that grew continuously until that point (e.g., living corals, living trees). We could refine our fossil corals framework with a mixed approach, where the age of tie points would be allowed to vary according to their distribution (e.g., a Gaussian), and the layer-count model would be extended on either side.

Finally, our optimization scheme was shown to be effective only in extremely restricted situations (error-free measurements of $\delta^{18} \mathrm{O}$, age model ensemble spanning the trueage model). It remains to be seen whether these conditions could ever be met in practice. One potential problem is the fact that the "clock" used to synchronize the records does not beat periodically: ENSO is only a quasi-periodic phenomenon, even in the GFDL CM2.0 model. Perhaps a more regular (annual, semi-annual) cycle would provide stronger synchronization constraints (but it would limit the analysis to records that have seasonal or better resolution). Alternatively, one could restrict the optimization process to small, regional ensembles of proxies that share a stronger common signal, much like dendrochronological approaches.

With these caveats in mind, several points deserve mention. First, the simple example of Fig. 2 demonstrates how miscounting errors may produce an apparent amplitude modulation of otherwise stationary signals, producing spurious trends in the average derived from them. Because climate reconstruction methods rely in some fashion on a weighted average of observations assumed to be contemporaneous, this may partially explain why many ENSO reconstructions (e.g., Mann et al., 2000; Wilson et al., 2010; McGregor et al., 2010; Li et al., 2011; Emile-Geay et al., 2013) display increasing trends in ENSO variance over time (McGregor et al., 2013). As pointed out in the latter study, computing ENSO variance on individual records prior to averaging them together is more robust to chronological errors. In the meantime, inter- preting trends in variance obtained from the average of ageuncertain records as reflecting a response to external forcing may be perilous. At the very least, a probabilistic model such as the one proposed here can provide a null hypothesis against which to assess such trends.

More generally, a model such as this one may be used to evaluate the plausible impact of dating uncertainties on all manner of inferences derived from time-uncertain records. Just as proxy system models are now becoming a standard tool to interpret environmental controls in paleoclimate proxies, chronological models should become an integral component of proxy system models for age-uncertain paleodata, so that they may be used to improve interpretation, reconstruction, uncertainty estimation, and data-model comparison studies (Evans et al., 2013). Because chronological errors might themselves depend on climatic events (see Introduction), a complete proxy system model should in fact allow environmental controls to influence chronological information.

We hope this study stimulates a discussion on how to best represent chronological uncertainty in layer-counted proxy archives and leads to a better characterization of these uncertainties.

Acknowledgements. M. Comboul, J. Emile-Geay, M. N. Evans, N. Mirnateghi, and D. M. Thompson acknowledge funding from NOAA award NA10OAR4310115. The authors also acknowledge the anonymous reviewer's effort in making useful comments that improved the paper. Matlab code implementing the age model ensembles is freely available on the Common Climate Google Code repository (https://code.google.com/p/common-climate/) (will be released after manuscript acceptance).

Edited by: P. Braconnot

\section{References}

Abram, N. J., Gagan, M. K., Cole, J. E., Hantoro, W. S., and Mudelsee, M.: Recent intensification of tropical climate variability in the Indian Ocean, Nat. Geosci., 1, 849-853, doi:10.1038/ngeo357, 2008 .

Abramowitz, M. and Stegun, I. A.: Handbook of Mathematical Functions, National Bureau of Standards, Applied Math \# 55, Dover Publications, 1965.

Alibert, C. and Kinsley, L.: A 170-year Sr/Ca and Ba/Ca coral record from the western Pacific warm pool: 2. A window into variability of the New Ireland Coastal Undercurrent, J. Geophys. Res., 113, 1-10, doi:10.1029/2007JC004263, 2008.

Alley, R. B., Mayewski, P. A., Sowers, T., Stuiver, M., Taylor, K. C., and Clark, P. U.: Holocene climatic instability: A prominent, widespread event $8200 \mathrm{yr}$ ago, Geology, 25, 483-486, doi:10.1130/0091-7613(1997)025<0483:HCIAPW>2.3.CO;2, 1997a.

Alley, R. B., Shuman, C. A., Meese, D. A., Gow, A. J., Taylor, K. C., Cuffey, K. M., Fitzpatrick, J. J., Grootes, P. M., Zielinski, G. A., Ram, M., Spinelli, G., and Elder, B.: Visual-stratigraphic dating 
of the GISP2 ice core: Basis, reproducibility, and application, J. Geophys. Res., 102, 26367-26381, doi:10.1029/96JC03837, 1997b.

Anchukaitis, K. J. and Tierney, J. E.: Identifying coherent spatiotemporal modes in time-uncertain proxy paleoclimate records, Clim. Dynam., 41, 1291-1306, doi:10.1007/s00382-012-1483-0, 2012.

Asami, R., Yamada, T., Iryu, Y., Quinn, T. M., Meyer, C. P., and Pauley, G.: Interannual and decadal variability of the western Pacific sea surface condition for the years 1787-2000: Reconstruction based on stable isotope record from a Guam coral, J. Geophys. Res., 110, C05018, doi:10.1029/2004JC002555, 2005.

Ault, T. R., Cole, J. E., Evans, M. N., Barnett, H., Abram, N. J., Tudhope, A. W., and Linsley, B. K.: Intensified decadal variability in tropical climate during the late 19th century, Geophys. Res. Lett., 36, L08602, doi:10.1029/2008GL036924, 2009.

Bender, M. L.: Orbital tuning chronology for the Vostok climate record supported by trapped gas composition, Earth Planet. Sc. Lett., 204, 275-289, doi:10.1016/S0012-821X(02)00980-9, 2002.

Blaauw, M.: Methods and code for "classical" age-modelling of radiocarbon sequences, Quat. Geochronol., 5, 512 - 518, doi:10.1016/j.quageo.2010.01.002, 2010.

Blaauw, M.: Out of tune: the dangers of aligning proxy archives, Quaternary Sci. Rev., 36, 38-49, doi:10.1016/j.quascirev.2010.11.012, 2012.

Blaauw, M. and Christen, J. A.: Flexible paleoclimate age-depth models using an autoregressive gamma process, Bayesian Analysis, 6, 457-474, doi:10.1214/11-BA618, 2011.

Boiseau, M., Juillet-Leclerc, A., Yiou, P., Salvat, B., Isdale, P., and Guillaume, M.: Atmospheric and oceanic evidences of El NiñoSouthern Oscillation events in the south central Pacific Ocean from coral stable isotopic records over the last 137 years, Paleoceanography, 13, 671-685, doi:10.1029/98PA02502, 1998.

Breitenbach, S. F. M., Rehfeld, K., Goswami, B., Baldini, J. U. L., Ridley, H. E., Kennett, D. J., Prufer, K. M., Aquino, V. V., Asmerom, Y., Polyak, V. J., Cheng, H., Kurths, J., and Marwan, N.: COnstructing Proxy Records from Age models (COPRA), Clim. Past, 8, 1765-1779, doi:10.5194/cp-8-1765-2012, 2012.

Broomhead, D. and King, G. P.: Extracting qualitative dynamics from experimental data, Physica D, 20, 217-236, doi:10.1016/0167-2789(86)90031-X, 1986.

Brown, F. H., Sarna-Wojcicki, A. M., Meyer, C. E., and Haileab, B.: Correlation of Pliocene and Pleistocene tephra layers between the Turkana Basin of East Africa and the Gulf of Aden, Quatern. Int., 13-14, 55-67, doi:10.1016/1040-6182(92)90010-Y, 1992.

Calvo, E., Marshall, J. F., Pelejero, C., McCulloch, M. T., Lough, J. M., and Isdale, P. J.: Interdecadal climate variability in the Coral Sea since 1708 A.D., Palaeogeogr. Palaeocl,, 248, 190201, 2007.

Capotondi, A., Wittenberg, A., and Masina, S.: Spatial and temporal structure of tropical Pacific interannual variability in 20th century coupled simulations, Ocean Model., 15, 274-298, 2006.

Chakrabarty, K., Sitharama Iyengar, S., Qi, H., and Cho, E.: Grid Coverage for Surveillance and Target Location in Distributed Sensor Networks, IEEE T. Comput., 51, 1448-1453, 2002.

Charles, C. D., Hunter, D. E., and Fairbanks, R. G.: Interaction Between the ENSO and the Asian Monsoon in a
Coral Record of Tropical Climate, Science, 277, 925-928, doi:10.1126/science.277.5328.925, 1997.

Charles, C. D., Cobb, K., Moore, M. D., and Fairbanks, R. G.: Monsoon-tropical ocean interaction in a network of coral records spanning the 20th century, Mar. Geol., 201, 207-222, doi:10.1016/S0025-3227(03)00217-2, 2003.

Chave, A. D., Thomson, D. J., and Ander, M. E.: On the robust estimation of power spectra, coherences, and transfer functions, J. Geophys. Res., 92, 633-648, doi:10.1029/JB092iB01p00633, 1987.

Cobb, K. M., Charles, C. D., and Hunter, D. E.: A central tropical Pacific coral demonstrates Pacific, Indian, and Atlantic decadal climate connections, Geophys. Res. Lett., 28, 22092212, doi:10.1029/2001GL012919, 2001.

Cobb, K. M., Charles, C. D., Cheng, H., and Edwards, R. L.: El Niño/Southern Oscillation and tropical Pacific climate during the last millennium, Nature, 424, 271-276, 2003.

Cobb, K. M., Westphal, N., Sayani, H. R., Watson, J. T., Lorenzo, E. D., Cheng, H., Edwards, R. L., and Charles, C. D.: Highly Variable El Niño-Southern Oscillation Throughout the Holocene, Science, 339, 67-70, 2013.

Cook, E. R. and Kairiukstis, L. A.: Methods of dendrochronology: Applications in the environmental sciences, Springer, ISBN: 07923-0586-8, 1990.

Damassa, T. D., Cole, J. E., Barnett, H. R., Ault, T. R., and McClanahan, T. R.: Enhanced multidecadal climate variability in the seventeenth century from coral isotope records in the western Indian Ocean, Paleoceanography, 21, PA2016, doi:10.1029/2005PA001217, 2006.

De Ridder, F., Pintelon, R., Schoukens, J., Gillikin, D. P., André, L., Baeyens, W., de Brauwere, A., and Dehairs, F.: Decoding nonlinear growth rates in biogenic environmental archives, Geochem. Geophy. Geosy., 5, doi:10.1029/2004GC000771, 2004.

DeLong, K. L., Quinn, T. M., and Taylor, F. W.: Reconstructing twentieth-century sea surface temperature variability in the southwest Pacific: A replication study using multiple coral $\mathrm{Sr} / \mathrm{Ca}$ records from New Caledonia, Paleoceanography, 22, PA4212, doi:10.1029/2007PA001444, 2007.

DeLong, K. L., Flannery, J. A., Maupin, C. R., Poore, R. Z., and Quinn, T. M.: A coral Sr/Ca calibration and replication study of two massive corals from the Gulf of Mexico, Palaeogeogr. Palaeocl., 307, 117-128, 2011.

DeLong, K. L., Quinn, T. M., Taylor, F. W., Shen, C.-C., and Lin, K.: Improving coral-base paleoclimate reconstructions by replicating 350 years of coral $\mathrm{Sr} / \mathrm{Ca}$ variations, Palaeogeogr. Palaeocl., 373, 6-24, 2013.

Douglass, A. E.: Crossdating in dendrochronology, J. Forest., 39, 825-831, 1941.

Emile-Geay, J. and Eshleman, J. A.: Toward a semantic web of paleoclimatology, Geochem. Geophy. Geosy., 14, 457-469, doi:10.1002/ggge.20067, 2013.

Emile-Geay, J., Cobb, K., Mann, M., and Wittenberg, A. T.: Estimating Central Equatorial Pacific SST variability over the Past Millennium. Part 2: Reconstructions and Implications, J. Climate, 26, 2329-2352, doi:10.1175/JCLI-D-11-00511.1, 2013.

Evans, M., Tolwinski-Ward, S., Thompson, D., and Anchukaitis, K.: Applications of proxy system modeling in high resolution paleoclimatology, Quaternary Sci. Rev., 76, 16-28, 2013. 
Evans, M. N., Kaplan, A., and Cane, M. A.: Optimal sites for coralbased reconstruction of global sea surface temperature, Paleoceanography, 13, 502-516, doi:10.1029/98PA02132, 1998.

Evans, M. N., Kaplan, A., and Cane, M. A.: Intercomparison of coral oxygen isotope data and historical sea surface temperature (SST): Potential for coral-based SST field reconstructions, Paleoceanogr., 15, 551-562, 2000.

Evans, M. N., Kaplan, A., and Cane, M. A.: Pacific sea surface temperature field reconstruction from coral $\delta^{18} \mathrm{O}$ data using reduced space objective analysis, Paleoceanogr., 17, 7-1, doi:10.1029/2000PA000590, 2002.

Fairbanks, R. G. and Dodge, R. E.: Annual periodicity of the ${ }^{18} \mathrm{O} /{ }^{16} \mathrm{O}$ and ${ }^{13} \mathrm{C} /{ }^{12} \mathrm{C}$ ratios in the coral Montastrea annularis, Geochim. Cosmochim. Ac., 43, 1009-1020, 1979.

Felis, T., Pätzold, J., Loya, Y., Fine, M., Nawar, A. H., and Wefer, G.: A coral oxygen isotope record from the northern Red Sea documenting NAO, ENSO, and North Pacific teleconnections on Middle East climate variability since the year 1750, Paleoceanography, 15, 679-694, doi:10.1029/1999PA000477, 2000.

Fraedrich, K.: Estimating the Dimensions of Weather and Climate Attractors, J.Atmos. Sci., 43, 419-432, doi:10.1175/15200469(1986)043<0419:ETDOWA>2.0.CO;2, 1986.

Fritts, H. C.: Tree Rings and Climate, 567 pp., Academic Press, 1976.

Grootes, P. M., Stuiver, M., White, J. W. C., Johnsen, S., and Jouzel, J.: Comparison of oxygen isotope records from the GISP2 and GRIP Greenland ice cores, Nature, 366, 552-554, doi:10.1038/366552a0, 1993 .

Guttman, I.: Statistical tolerance regions: classical and Bayesian, vol. 26, Griffin London, 1970.

Haam, E. and Huybers, P.: A test for the presence of covariance between time-uncertain series of data with application to the Dongge Cave speleothem and atmospheric radiocarbon records, Paleoceanography, 25, PA2209, doi:10.1029/2008PA001713, 2010.

Hamming, R. W.: Error Detecting and Error Correcting Codes, Bell Syst. Tech. J., 29, 147-160, 1950.

Hays, J. D., Imbrie, J., and Shackleton, N. J.: Variations in the Earth's Orbit: Pacemaker of the Ice Ages, Science, 194, 11211132, 1976.

Hendy, E. J., Gagan, M. K., Alibert, C. A., McCulloch, M. T., Lough, J. M., and Isdale, P. J.: Abrupt Decrease in Tropical Pacific Sea Surface Salinity at End of Little Ice Age, Science, 295, 1511-1514, doi:10.1126/science.1067693, 2002.

Huybers, P. and Wunsch, C.: A depth-derived Pleistocene age model: Uncertainty estimates, sedimentation variability, and nonlinear climate change, Paleoceanogr., 19, PA1028, doi:10.1029/2002PA000857, 2004.

Isdale, P. J., Stewart, B. J., Tickle, K. S., and Lough, J. M.: Palaeohydrological variation in a tropical river catchment: a reconstruction using fluorescent bands in corals of the Great Barrier Reef, Australia, The Holocene, 8, 1-8, doi:10.1191/095968398670905088, 1998.

Juillet-Leclerc, A., Thiria, S., Naveau, P., Delcroix, T., Le Bec, N., Blamart, D., and Corrège, T.: SPCZ migration and ENSO events during the 20th century as revealed by climate proxies from a Fiji coral, Geophys, Res. Lett., 33, L17710, doi:10.1029/2006GL025950, 2006.
Knutson, T. R., Delworth, T. L., Dixon, K. W., Held, I. M., Lu, J., Ramaswamy, V., Schwarzkopf, M. D., Stenchikov, G., and Stouffer, R. J.: Assessment of Twentieth-Century Regional Surface Temperature Trends Using the GFDL CM2 Coupled Models, J. Climate, 19, 1624-1651, doi:10.1175/JCLI3709.1, 2006.

Kug, J.-S., Choi, J., An, S.-I., Jin, F.-F., and Wittenberg, A. T. Warm pool and cold tongue El Niño events as simulated by the GFDL CM2.1 coupled GCM, J. Climate, 23, 1226-1239, doi:10.1175/2009JCLI43293.1, 2010.

Kuhnert, H., Pätzold, J., Hatcher, B., Wyrwoll, K. H., Eisenhauer, A., Collins, L. B., Zhu, Z. R., and Wefer, G.: A 200-year coral stable oxygen isotope record from a highlatitude reef off Western Australia, Coral Reefs, 18, 1-12, doi:10.1007/s003380050147, 1999.

Kuhnert, H., Pätzold, J., Wyrwoll, K.-H., and Wefer, G.: Monitoring climate variability over the past 116 years in coral oxygen isotopes from Ningaloo Reef, Western Australia, Int. J. Earth Sci., 88, 725-732, doi:10.1007/s005310050300, 2000

Li, J., Xie, S.-P., Cook, E. R., Huang, G., D’Arrigo, R., Liu, F., $\mathrm{Ma}$, J., and Zheng, X.-T.: Interdecadal modulation of El Niño amplitude during the past millennium, Nature Climate Change, $1,114-118,2011$.

Linsley, B. K., Dunbar, R. B., Wellington, G. M., and Mucciarone, D. A.: A coral-based reconstruction of intertropical convergence zone variability over Central America since 1707, J. Geophys. Res., 99, 9977-9994, doi:10.1029/94JC00360, 1994.

Linsley, B. K., Ren, L., Dunbar, R. B., and Howe, S. S.: El Niño Southern Oscillation (ENSO) and decadal-scale climate variability at $10^{\circ} \mathrm{N}$ in the eastern Pacific from 1893 to 1994: A coralbased reconstruction from Clipperton Atoll, Paleoceanography, 15, 322-335, doi:10.1029/1999PA000428, 2000.

Linsley, B. K., Kaplan, A., Gouriou, Y., Salinger, J., deMenocal, P. B., Wellington, G. M., and Howe, S. S.: Tracking the extent of the South Pacific Convergence Zone since the early 1600s, Geochem. Geophy. Geosy., 7, doi:10.1029/2005GC001115, 2006.

Linsley, B. K., Zhang, P., Kaplan, A., Howe, S. S., and Wellington, G. M.: Interdecadal-decadal climate variability from multicoral oxygen isotope records in the South Pacific Convergence Zone region since 1650 A.D., Paleoceanography, 23, PA2219, doi:10.1029/2007PA001539, 2008

Lisiecki, L. E. and Raymo, M. E.: A Pliocene-Pleistocene stack of 57 globally distributed benthic $\delta^{18} \mathrm{O}$ records, Paleoceanography, 20, PA1003, doi:10.1029/2004PA001071, 2005.

Mann, M., Gilleb, E., Bradley, R., Hughes, M., Overpeck, J., Keimigc, F., and Gross, W.: Global temperature patterns in past centuries: An interactive presentation, Earth Interact., 4, 1-29, 2000.

Marcott, S. A., Shakun, J. D., Clark, P. U., and Mix, A. C.: A Reconstruction of Regional and Global Temperature for the Past 11,300 Years, Science, 339, 1198-1201, doi:10.1126/science.1228026, 2013.

Martinson, D. G., Menke, W., and Stoffa, P.: An Inverse Approach to Signal Correlation, J. Geophys. Res., 87, 4807-4818, doi:10.1029/JB087iB06p04807, 1982.

McGregor, S., Timmermann, A., and Timm, O.: A unified proxy for ENSO and PDO variability since 1650, Clim. Past, 6, 1-17, doi:10.5194/cp-6-1-2010, 2010 
McGregor, S., Timmermann, A., England, M. H., Elison Timm, O., and Wittenberg, A. T.: Inferred changes in El Niño-Southern Oscillation variance over the past six centuries, Clim. Past, 9, 2269 2284, doi:10.5194/cp-9-2269-2013, 2013.

Mudelsee, M., Scholz, D., Röthlisberger, R., Fleitmann, D., Mangini, A., and Wolff, E. W.: Climate spectrum estimation in the presence of timescale errors, Nonlin. Processes Geophys., 16, 43-56, doi:10.5194/npg-16-43-2009, 2009.

PAGES2K Consortium: Continental-scale temperature variability during the past two millennia, Nat. Geosci, 6, 339-346, doi:10.1038/ngeo1797, 2013

Pfeiffer, M., Timm, O., Dullo, W.-C., and Podlech, S.: Oceanic forcing of interannual and multidecadal climate variability in the southwestern Indian Ocean: Evidence from a 160 year coral isotopic record (La Réunion, $55^{\circ} \mathrm{E}, 21^{\circ} \mathrm{S}$ ), Paleoceanography, 19, doi:10.1029/2003PA000964, 2004.

Quinn, T. M., Crowley, T. J., Taylor, F. W., Henin, C., Joannot, P., and Join, Y.: A multicentury stable isotope record from a New Caledonia coral: Interannual and decadal sea surface temperature variability in the southwest Pacific since 1657 A.D., Paleoceanography, 13, 412-426, doi:10.1029/98PA00401, 1998.

Quinn, T. M., Taylor, F. W., and Crowley, T. J.: Coral-based climate variability in the Western Pacific Warm Pool since 1867, J. Geophys. Res., 111, C11006, doi:10.1029/2005JC003243, 2006.

Ramirez, D., Via, J., and Santamaria, I.: A generalization of the magnitude squared coherence spectrum for more than two signals: definition, properties and estimation, in: Acoustics, Speech and Signal Processing, 2008. ICASSP 2008. IEEE International Conference on, 31 March-4 April 2008, 3769-3772, doi:10.1109/ICASSP.2008.4518473, 2008.

Ramirez, D., Via, J., Santamaria, I., and Scharf, L. L.: Detection of Spatially Correlated Gaussian Time Series, IEEE T. Signal Proces., 58, 5006-5015, 2010.

Rhines, A. and Huybers, P.: Estimation of spectral power laws in time uncertain series of data with application to the Greenland Ice Sheet Project $2 \delta^{18} \mathrm{O}$ record, J. Geophys. Res., 116, D01103, doi:10.1029/2010JD014764, 2011.

Schoellhamer, D. H.: Singular spectrum analysis for time series with missing data, Geophys. Res. Lett., 28, 3187-3190, doi:10.1029/2000GL012698, 2001.

Seimon, A.: Improving climatic signal representation in tropical ice cores: A case study from the Quelccaya Ice Cap, Peru, Geophys. Res. Lett., 30, 1772, doi:10.1029/2003GL017191, 2003.

Shen, C.-C., Lin, K., Duan, W., Jiang, X., Partin, J. W., Edwards, R. L., Cheng, H., and Tan, M.: Testing the annual nature of speleothem banding, Scientific Reports, 3, 2633, doi:10.1038/srep02633, 2013.

Skellam, J. G.: The Frequency Distribution of the Difference Between Two Poisson Variates Belonging to Different Populations, J. R. Stat. Soc. Ser. A-G., 109, 296 pp., 1946.

St. George, S., Ault, T. R., and Torbenson, M. C. A.: The rarity of absent growth rings in Northern Hemisphere forests outside the American Southwest, Geophys. Res. Lett., 40, 3727-3731, doi:10.1002/grl.50743, 2013.

Stokes, M. A. and Smiley, T. L.: An Introduction to Tree-Ring Dating, The University of Chicago Press, 1996.

Suhov, Y. and Kelbert, M.: Probability and statistics by example: Markov chains: a primer in random processes and their applications, Cambridge University Press, 2008.
Thompson, D. M., Ault, T. R., Evans, M. N., Cole, J. E., and EmileGeay, J.: Comparison of observed and simulated tropical climate trends using a forward model of coral of $\delta^{18} \mathrm{O}$, Geophys. Res. Lett., 38, L14706, doi:10.1029/2011GL048224, 2011.

Thompson, L. G., Mosley-Thompson, E., Bolzan, J. F., and Koci, B. R.: A 1500-Year Record of Tropical Precipitation in Ice Cores from the Quelccaya Ice Cap, Peru, Science, 229, 971-973, doi:10.1126/science.229.4717.971, 1985.

Thomson, D. J.: Spectrum estimation and harmonic analysis, Proceedings of the IEEE, 70, 1055-1096, 1982.

Tierney, J. E., Smerdon, J. E., Anchukaitis, K. J., and Seager, R.: Multidecadal variability in East African hydroclimate controlled by the Indian Ocean, Nature, 493, 389392,doi:10.1038/nature11785, 2013.

Tingley, M. P. and Huybers, P.: Recent temperature extremes at high northern latitudes unprecedented in the past 600 years, Nature, 496, 201-205, doi:10.1038/nature11969, 2013.

Tudhope, A. W., Chilcott, C. P., McCulloch, M. T., Cook, E. R., Chappell, J., Ellam, R. M., Lea, D. W., Lough, J. M., and Shimmield, G. B.: Variability in the El Niño-Southern Oscillation Through a Glacial-Interglacial Cycle, Science, 291, 1511-1517, doi:10.1126/science.1057969, 2001.

Urban, F. E., Cole, J. E., and Overpeck, J. T.: Influence of mean climate change on climate variability from a 155 -year tropical Pacific coral record, Nature, 407, 989-993, 2000.

Vautard, R. and Ghil, M.: Singular spectrum analysis in nonlinear dynamics, with applications to paleoclimatic time series, Physica D, 35, 395-424, 1989.

Vecchi, G. A., Soden, B. J., Wittenberg, A. T., Held, I. M., Leetmaa, A., and Harrison, M. J.: Weakening of tropical Pacific atmospheric circulation due to anthropogenic forcing, Nature, 441, 73-76, 2006.

Wang, Y. J., Cheng, H., Edwards, R. L., An, Z. S., Wu, J. Y., Shen, C.-C., and Dorale, J. A.: A High-Resolution Absolute-Dated Late Pleistocene Monsoon Record from Hulu Cave, China, Science, 294, 2345-2348, doi:10.1126/science.1064618, 2001.

Wigley, T. M. L., Jones, P. D., and Briffa, K. R.: Cross-dating methods in dendrochronology, J. Archaeol. Sci., 14, 51-64, 1987.

Wilson, R., Cook, E., D’Arrigo, R., Riedwyl, N., Evans, M. N., Tudhope, A., and Allan, R.: Reconstructing ENSO: the influence of method, proxy data, climate forcing and teleconnections, J. Quaternary Sci., 25, 62-78, doi:10.1002/jqs.1297, 2010.

Wittenberg, A. T., Rosati, A., Lau, N.-C., and Ploshay, J. J.: GFDL's CM2 Global Coupled Climate Models. Part III: Tropical Pacific Climate and ENSO, J. Climate, 19, 698-722, doi:10.1175/JCLI3631.1, 2006.

Xie, S.-P., Deser, C., Vecchi, G. A., Ma, J., Teng, H., and Wittenberg, A. T.: Global warming pattern formation: Sea surface temperature and rainfall, J. Climate, 23, 966-986, doi:10.1175/2009JCLI3329.1, 2010.

Yamaguchi, D. K.: A simple method for cross-dating increment cores from living trees, Can. J. Forest Res., 21, 414-416, 1991.

Zinke, J., Dullo, W.-C., Heiss, G. A., and Eisenhauer, A.: ENSO and Indian Ocean subtropical dipole variability is recorded in a coral record off southwest Madagascar for the period 1659 to 1995, Earth Planet. Sc. Lett., 228, 177-194, doi:10.1016/j.eps1.2004.09.028, 2004. 


\section{Appendix A}

\section{Stochastic model derivation}

The stochastic model used to characterize the age uncertainties may be derived as follows: let us denote by $\left\{N_{i}: i=\right.$ $1,2, \ldots, n\} n$ independent and identically distributed random variables on the probability space $\{\Omega, \Sigma, \operatorname{Pr}\}$ representing the miscounting events on observed layers. Each $N_{i}$ is a counting process on $\left[t_{i}, t_{i+1}\right)$ taking values in the sample set $\Omega$ of non-negative integers and $N_{i}=0$ if the layer was counted accurately. Let the stochastic process $\left\{N(t): t_{1} \leq t \leq t_{n}\right\}$ equal the number of age perturbations in our data in the time interval $\left[t_{1}, t_{n}\right]$; then $N\left(t_{i}\right)=\sum_{k=1}^{i} N_{k}$ is also a counting process. Because of the earlier assumption on the most recent observation being known exactly, we can write that $N\left(t_{1}\right)=0$. We also parameterize the miscounting error rate by $\theta$ such that $E\left(N_{i}\right)=\theta$, and we can prescribe our simulations to accumulate on average $\theta n$ perturbations. Recognizing that the chances of miscounting more than 2 years per band are slight, one may write

$$
\begin{aligned}
& \operatorname{Pr}\{N(t+h)-N(t)=1\}=\theta h+o(h), \\
& \operatorname{Pr}\{N(t+h)-N(t) \geq 2\}=o(h)^{2},
\end{aligned}
$$

One recognizes $N(t)$ as a Poisson process with rate parame$\operatorname{ter} \theta$ (e.g., Suhov and Kelbert, 2008, theorem 2.3.2b). When the level of confidence in a particular chronology is such that $\operatorname{Pr}\left(N_{i}\right)>1$ is negligible, a Bernoulli process would be a suitable approximation for $N(t)$ with $\operatorname{Pr}\left(N_{i}=1\right)=\theta$, and $N\left(t_{i}\right)$ would follow a Binomial distribution $\mathcal{B}(i, \theta)$. Age perturbations when counting layers fall in one of two categories: one can either miss (type 1) or double-count (type 2) a band, so we classify perturbation events into those two types. Let $\left\{P_{i}^{\theta_{1}}: i=1,2, \ldots, n\right\}$ count the number of missing layers between layers $i-1$ and $i$ and $\left\{P_{i}^{\theta_{2}}: i=1,2, \ldots, n\right\}$ count the number of duplications of layer $i$ with rate parameter $\theta_{1}$ and $\theta_{2}$, respectively; then, if we assume that the two types of events are independent, we can write that $N_{i}=P_{i}^{\theta_{1}}+P_{i}^{\theta_{2}}$ and $\theta=\theta_{1}+\theta_{2}$. The assumption of independence simplifies the problem's treatment, though it is obviously an idealization. In practice, the probability of a layer being counted as part of both categories is generally so low that it does not materially affect the results. A stochastic parameterization of the increment matrix may thus be expressed as follows:

$\forall i \in[1, n-1], \quad \Delta_{i}=1+P_{i}^{\theta_{1}}-\min \left(P_{i}^{\theta_{2}}, 1\right)$,

where the perturbations $\left\{P_{i}^{\theta_{k}}: k=1,2\right\}$ are random variables representing Poisson increments in $\left[t_{i}, t_{i+1}\right)$ with rate $\theta_{k}>0$ or the outcomes of a Bernoulli process with trial probability $\theta_{k}$. In both instances, one may choose parameters so that the variables are zero most of time, except for a relatively small

\footnotetext{
${ }^{2} f(h)=o(h)$ is a function such that $\frac{f(h)}{h}$ goes to zero with $h$
}

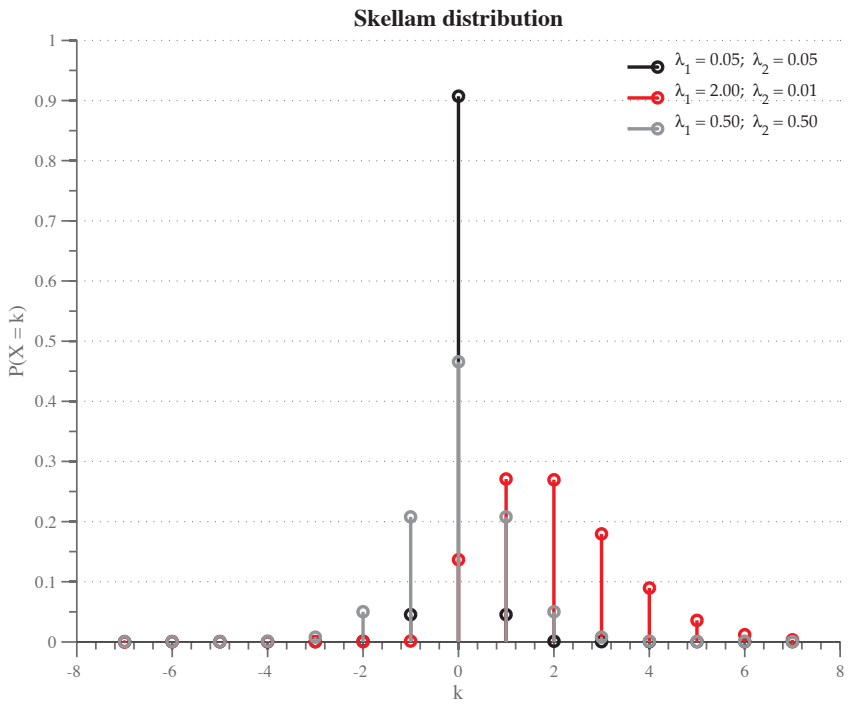

Fig. A1. Skellam probability mass functions for different values of its parameters $\lambda_{1}$ and $\lambda_{2}$.

fraction (say $5 \%$ ) when they are positive, so $\Delta_{i}>1$ when $P_{i}^{\theta_{1}}>0$ (i.e., a year is missing) or $\Delta_{i}<1$ when $P_{i}^{\theta_{2}}>0$ (i.e., a band was doubled). It follows that the chronology verifies

$t_{i}=t_{\mathrm{f}}-i-\sum_{k=1}^{i} P_{k}^{\theta_{1}}+\sum_{k=1}^{i} \min \left(P_{k}^{\theta_{2}}, 1\right)$.

Extending the model formulation to multivariate banded data sets, and indexing by $j$ the record location, the matrix of time increments is expressed as

$\Delta_{\mathrm{ij}}=1+P_{i}^{\theta_{1 \mathrm{j}}}-\min \left(P_{i}^{\theta_{2 \mathrm{j}}}, 1\right)$

and the chronology matrix verifies

$\tau_{\mathrm{ij}}=t_{\mathrm{f}}-i-\sum_{k=1}^{i} P_{k}^{\theta_{1 \mathrm{j}}}+\sum_{k=1}^{i} \min \left(P_{k}^{\theta_{2 \mathrm{j}}}, 1\right)$.

In the Poisson case, if we denote by $N_{1}(t)$ and $N_{2}(t)$ the number of events $\sum_{k} P_{k}^{\theta_{1}}$ and $\sum_{k} P_{k}^{\theta_{2}}$ until time $t$, respectively, then the difference between the two Poisson processes $N_{1}(t)-N_{2}(t)$ is known to follow a Skellam distribution (Skellam, 1946) with parameters $\lambda_{1}=\theta_{1} t$ and $\lambda_{2}=\theta_{2} t$, which is given by

$\operatorname{Pr}\left\{N_{1}(t)-N_{2}(t)=k\right\}=e^{-\left(\lambda_{1}+\lambda_{2}\right)}\left(\frac{\lambda_{1}}{\lambda_{2}}\right)^{k / 2} \mathbf{I}_{|k|}\left(2 \sqrt{\lambda_{1} \lambda_{2}}\right)$,

where $\mathbf{I}_{k}(x)$ is a modified Bessel function of the first kind (e.g., Abramowitz and Stegun, 1965). The Skellam distribution is plotted in Fig. A1, and we here summarize its main properties: 
1. Its mean is equal to $\lambda_{1}-\lambda_{2}$, its variance to $\lambda_{1}+\lambda_{2}$.

2. For $\lambda_{1}=\lambda_{2}$, the distribution is symmetric, centered at zero.
3. For $\lambda_{1}=\lambda_{2}$ large enough, it is well approximated by a normal distribution $\mathcal{N}\left(0, \lambda_{1}+\lambda_{2}\right)$; thus the difference between the Poisson model and the binomial model (which also converges to a normal distribution) becomes negligible. 